\title{
Effects of growth stage and growing degree day accumulations on triticale forages: 2 . In vitro disappearance of neutral detergent fiber
}

\author{
W. K. Coblentz, ${ }^{11}$ M. S. Akins, † K. F. Kalscheur,ł G. E. Brink, $\ddagger$ and J. S. Cavadini§ \\ *USDA Agricultural Research Service, US Dairy Forage Research Center, Marshfield, WI 54449 \\ †Department of Dairy Science, University of Wisconsin, Madison 53706 \\ łUSDA Agricultural Research Service, US Dairy Forage Research Center, Madison, WI 53706 \\ §University of Wisconsin Marshfield Agricultural Research Station, Marshfield 54449
}

\begin{abstract}
The use of winter triticale (X Triticosecale Wittmack) in dairy-cropping systems has expanded greatly in recent years, partly because of its value as a forage crop but also to improve land stewardship by providing winter ground cover. Our objectives were to use 2-pool and 3-pool nonlinear models to characterize in vitro disappearance of neutral detergent fiber (NDF) and then describe the relationship between estimated parameters from those models with plant growth stage or growing degree days (GDD) $>5^{\circ} \mathrm{C}$ for winter triticale forages harvested during 2016 and 2017 in Marshfield, Wisconsin. Forages were harvested from replicated field plots each year at growth stages ranging from stem elongation to soft dough. All NDF analyses included use of sodium sulfite and heat-stable $\alpha$-amylase with residual fiber corrected for contaminant ash (asNDFom). Nonlinear 3-pool models for in vitro disappearance of asNDFom that included fast (Bfast) and slow (Bslow) disappearance pools as well as an associated disappearance rate for each ( $\mathrm{K}_{\mathrm{d}}$ fast and $\mathrm{K}_{\mathrm{d}} \mathrm{slow}$, respectively) were easily fitted provided that a single discrete lag time was applied to both Bfast and Bslow pools to reduce the number of parameters to be estimated. An unresolved issue related to fitting 3-pool decay models was the incomplete recovery of asNDFom from immature triticale forages at $0 \mathrm{~h}$, which was partially resolved with 2 approaches that produced similar estimates of $\mathrm{K}_{\mathrm{d}}$ fast and $\mathrm{K}_{\mathrm{d}}$ slow. Most parameters obtained from 2- and 3-pool decay models for asNDFom could be related to growth stage or GDD using polynomial regression techniques, often with high coefficients of determination $\left(\mathrm{R}^{2}\right)$. For 3 -pool models of asNDFom disappearance, Bslow increased with plant maturity, but the associated $\mathrm{K}_{\mathrm{d}}$ slow
\end{abstract}

Received April 3, 2018.

Accepted May 28, 2018.

${ }^{1}$ Corresponding author: wayne.coblentz@ars.usda.gov ranged narrowly from 0.011 to $0.015 / \mathrm{h}$ and could not be related to growth stage or GDD by quartic, cubic, quadratic, or linear regression models. Despite different cultivars coupled with substantial differences in precipitation across years, single endpoint estimates of in vitro disappearance of asNDFom after 24,30 , or $48 \mathrm{~h}$ of incubation were closely related $\left(\mathrm{R}^{2} \geq 0.906\right)$ to growth stage and GDD by linear or quadratic regression models that were generally similar across production years. Typical recommendations for harvesting triticale at boot stage to facilitate the planting of a double crop are strongly supported by the extensive 30 - $\mathrm{h}$ in vitro disappearance of asNDFom at that growth stage, which was 63.1 and $64.8 \%$ of asNDFom during 2016 and 2017, respectively.

Key words: double cropping, harvest timing, in vitro fiber disappearance, triticale

\section{INTRODUCTION}

The use of triticale (X Triticosecale Wittmack) in dairy-cropping systems has expanded greatly in recent years, partly as a management tool to capture $\mathrm{N}$ from land-applied manure but also to improve stewardship of the land by providing winter ground cover. However, triticale also is recognized as a valuable forage crop (Maloney et al., 1999; McCormick et al., 2006; Baron et al., 2012) with potential for use across a range of livestock classes. Most production scenarios in the north-central United States target fall establishment after removal of corn for silage or soybeans (Schwarte et al., 2005; Gibson et al., 2007), followed by harvest as silage the following spring or early summer. Generally, a high-energy forage suitable for lactating dairy cows is obtained by harvesting when the flag leaf is fully emerged but no seed heads are visible (Kilcer et al., 2010). Using this management approach, triticale silage has been successfully substituted for corn silage in diets of lactating cows at a rate of $10 \%$ of dietary DM (Harper et al., 2017). However, harvests at the late milk to early dough stages of growth also have occurred 
commonly for cereal grain forages (McDonald et al., 1991; McCartney and Vaage, 1994; Kennelly and Weinberg, 2003), and this delayed harvest approach provides a considerable yield advantage $(>300 \%)$ over harvest at the boot stage of growth for triticale (Coblentz et al. 2018). Substantial yield differentials between harvests at the boot and soft dough stages of growth also have been reported for other cereal grain forages (Acosta et al., 1991; Edmisten et al., 1998). In one study where triticale silage was harvested at the soft dough stage of growth, it was observed to be less acceptable than barley or oat silage for beef heifers and sheep, based primarily on poorer palatability and reduced DMI (McCartney and Vaage, 1994). Therefore, there is a need for both conceptual and empirical information providing guidance to producers on how to best manage and use triticale forages. An important component within this effort is an in-depth characterization of in vitro NDF disappearance kinetics for these forages.

It has long been understood that forage fiber is not homogeneous, and it is incompletely digested by ruminants, which can be illustrated clearly by application of a Lucas test (Van Soest, 1982). Within the Lucas concept, an ideal feed fraction is a feed component for which a regression of the amount digested is directly proportional to the amount of that feedstuff component consumed, thereby yielding a slope of approximately 1. Some components, such as ADL, may exhibit no digestion regardless of intake (slope $=0$ ) and are also considered ideal. However, most fiber components, such as NDF, ADF, hemicellulose, and cellulose, are incompletely digested and are considered nonideal, resulting in a slope $<1$ but $>0$. The heterogeneous nature of forage fiber has long complicated nutritional models for dairy cattle as well as associated analysis techniques. In recent years, refinements in measuring in vitro NDF digestion to support existing nutritional models have emphasized (1) use of NDF measured with heat-stable $\alpha$-amylase and sodium sulfite and corrected for residual ash (asNDFom), (2) determinations of indigestible NDF following a 240-h in vitro or in situ digestion $(\mathbf{U})$, and (3) increased recognition that fiber digestion may be better characterized by more complex models that include rapidly and slowly degrading fiber pools (Raffrenato and Van Amburgh, 2010; Grant, 2015). In particular, these efforts have focused special attention on direct quantification of $U$ rather than relying on the calculated estimate $\mathrm{U}=(2.4 \times \mathrm{ADL}) / \mathrm{NDF} \times$ $100 \%$ proposed by Chandler et al. (1980). Historically, kinetics of NDF degradation have been fitted to firstorder 2-pool (2P) decay models comprising $\mathrm{U}$ and a potentially degradable NDF pool (B) using natural log (ln)-transformation or nonlinear regression techniques (Mertens and Loften, 1980; Nocek and English, 1986).
Recently, this analytical paradigm has been challenged by the concept that forage fiber is not homogeneous and that NDF degradation kinetics characterized by fast (Bfast), slow (Bslow), and U pools (3 pools; 3P) might better explain ruminal fermentation of NDF (Raffrenato and Van Amburgh, 2010; Grant, 2015; Mertens, 2016). This concept has been developed in conjunction with efforts to better estimate $U$ at extended incubation times $(\sim 240 \mathrm{~h})$, where plots of the natural logarithm of potentially digestible NDF remaining versus incubation time are curvilinear, suggesting that potentially digestible NDF may comprise fast- and slow-digested pools, each with a different digestion rate (Mertens, 2016). Initially, these concepts focused some attention on differences between forage types (Raffrenato and Van Amburgh, 2010); however, within-species effects of accumulated growing degree days (GDD) $>5^{\circ} \mathrm{C}$ or plant growth stage at harvest have not been investigated. In a companion report, we described the effects of growth stage or GDD on various indices of nutritive value (Coblentz et al., 2018). Based on the increased use of triticale forages in the north-central United States, our objectives were to use $2 \mathrm{P}$ and $3 \mathrm{P}$ nonlinear models to characterize in vitro disappearance of asNDFom (NDFD) and then describe the relationship between estimated parameters from those models with plant growth stage or GDD for triticale forages harvested during 2016 and 2017 in Marshfield, Wisconsin.

\section{MATERIALS AND METHODS}

\section{Forages}

2016 Harvest. All specifics regarding establishment of triticale, soil fertility, fertilization, weather, and sampling procedures are described in detail in a companion report (Coblentz et al., 2018), and only a brief summary of salient points relevant to the experimental design is repeated here. Twenty-five $3.7-\mathrm{m} \times 9.1-\mathrm{m}$ plots were established in 5 field blocks ( 5 plots/block) on September 30, 2015. Plots were no-till seeded into corn silage stubble with 'Forerunner' triticale (Legacy Seeds, Scandinavia, WI). Within each field block, the 5 plots were assigned randomly to 1 of 5 harvest dates based on a normal progression of advancing growth stages. During the spring and early summer of 2016, these growth stages and harvest dates were (1) stem elongation (May 19), (2) boot (May 25), (3) heading (May 31), (4) anthesis (June 9), and (5) soft dough (July 1). On each harvest date, 3 plants/plot were assessed for growth stage using the linear model suitable for serving as an independent variable for regression procedures (Stauss, 1994), where tillering $=20$ to 29, 
stem elongation $=30$ to 39 , booting $=40$ to 49 , heading $=50$ to 59 , anthesis $=60$ to 69 , seed development $=70$ to 79 , and seed ripening $=80$ to 89 .

2017 Harvest. On October 22, 2016, 'Tri-Cal' triticale (Byron Seeds LLC, Rockville, IN) was no-till seeded into soybean stubble, creating 5 field blocks consisting of 6 plots/block $(\mathrm{n}=30$ plots $)$. Although it was our intention to align growth stages at harvest across years, this was not possible due to the unseasonably wet conditions observed from April through June of 2017, when cumulative rainfall totaled $470 \mathrm{~mm}$ (Coblentz et al., 2018). As such, one complete field block (6 plots) was lost to flooding, and some harvests had to be delayed because of muddy field conditions. Actual growth stages and harvest dates for 2017 were (1) stem elongation (May 24), (2) boot (May 29), (3) late boot (June 2), (4) early anthesis (June 8), (5) watery seed (June 23), and (6) soft dough (June 30). Although 5 complete field blocks were planted, only 4 field blocks comprising 6 plots each $(\mathrm{n}=24)$ were actually harvested for analysis due to the aforementioned flooding. Three plants per plot were staged as described previously to provide a continuous (independent) variable for subsequent regression analysis.

\section{Laboratory Analysis}

Whole-plant triticale forages were dried under forced air and then ground through a 1-mm screen in a Thomas model 4 Wiley mill (Thomas Scientific, Swedesboro, NJ). Within the laboratory, a correction to absolute DM was determined by drying 1.0-g samples of each forage overnight in a convection oven at $105^{\circ} \mathrm{C}$. Initial concentrations of asNDFom were determined by digestion in neutral detergent that included heat-stable $\alpha$-amylase and sodium sulfite using the batch procedures outlined for an Ankom200 fiber analyzer by the manufacturer (Ankom Technology Corp., Macedon, NY). Following digestion in neutral detergent, NDF residues were corrected for residual ash by combustion in a muffle furnace at $500^{\circ} \mathrm{C}$ for $6 \mathrm{~h}$.

\section{In Vitro Rate Kinetics}

2016 Harvest. An assessment of in vitro disappearance of asNDFom was conducted on triticale forages harvested during the spring and early summer of 2016 using the Ankom Daisy II incubator system (Ankom Technology Corp.). Subsamples of each forage (0.30 g) were incubated within heat-sealed F57 fiber bags for 3 , $6,9,12,18,24,36,48,72,96,144$, or $240 \mathrm{~h}$ as recommended by Ankom Technology Corp. Each empty F-57 filter bag was prerinsed in acetone and air dried per instructions of the aforementioned manufacturer before loading and sealing the sample within the bag. The $0.30-\mathrm{g}$ sample size was used across all incubation times and was a procedural compromise between the sample size recommended by the manufacturer for short incubation times $(0.25 \mathrm{~g})$ and ensuring that adequate residue remained to accurately assess the asNDFom recovery following the 144- and 240-h incubations. Each triticale forage was subjected to quadruplicate incubations under the following conditions: (1) each combination of forage and incubation time $(\mathrm{n}=12$ jars $\times 25$ plots $=300$ samples/run) was represented (in singlet) within each of 4 runs; (2) each incubation jar contained 25 plot samples and 1 standard forage, plus 1 blank; (3) each incubation jar was located in a different box position (top right, top left, bottom right, and bottom left) during each of the 4 runs; (4) each jar containing a specific incubation time was evaluated at least once in each of the 3 incubator boxes; and (5) an independent thermometer was positioned within each incubator box to standardize each incubator to a common $39^{\circ} \mathrm{C}$ across all incubator boxes. Rumen fluid used in the inoculum was obtained from 2 nonlactating Holstein cows offered a forage-based diet $(12.6 \% \mathrm{CP}, 49.2 \% \mathrm{NDF}, 11.1 \%$ starch, and 59.0\% TDN; University of Wisconsin Soil and Forage Laboratory, Marshfield, WI) that included (DM basis) alfalfa haylage (53.4\%), corn silage (21.4\%), and chopped wheat straw (25.2\%). Rumen fluid was siphoned from each cow with a hand-operated pump through a ruminal cannula directly into prewarmed $\left(39^{\circ} \mathrm{C}\right)$ insulated bottles and then transported to the laboratory in a chest-type insulated cooler. Rumen fluid was filtered through 4 layers of cheesecloth, and $400 \mathrm{~mL}$ of rumen fluid with equal contributions from each donor cow was added to each incubation jar containing buffers and samples. The headspace within each incubation jar was purged with $\mathrm{CO}_{2}$ immediately after buffers and sample bags were added to the incubation jars for prewarming to $39^{\circ} \mathrm{C}$ and then immediately after rumen fluid was added to each jar before final lid placement before incubation.

Following incubation for the assigned time intervals, fiber bags containing residues of triticale forages were digested as described previously in neutral detergent using heat-stable $\alpha$-amylase and sodium sulfite. Following digestion, fiber residues were dried overnight in a convection oven at $105^{\circ} \mathrm{C}$, weighed, and then combusted in a muffle furnace at $500^{\circ} \mathrm{C}$ for $6 \mathrm{~h}$ to correct the residual fiber weight for contaminant ash. The quadruplicate values for each combination of forage and incubation time obtained from the 4 incubation runs were averaged as multiple within-sample observations before any calculation of rate kinetics.

Disappearance kinetics of asNDFom were calculated from 3 models. The $2 \mathrm{P}$ model was fitted by PROC 
NLIN of SAS (version 9.3; SAS Institute Inc., Cary, $\mathrm{NC})$ as

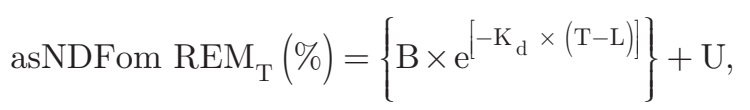

where asNDFom $\mathrm{REM}_{\mathrm{T}}=$ the percentage of asNDFom remaining at time $\mathrm{T}, \mathrm{B}=$ percentage of asNDFom degraded at a measurable rate, $\mathrm{e}=\mathrm{a}$ constant equal to 2.718 and the base of the natural logarithm, $\mathrm{K}_{\mathrm{d}}=$ disappearance rate of $\mathrm{B}(/ \mathrm{h}), \mathrm{T}=$ incubation time $(\mathrm{h}), \mathrm{L}=$ discrete lag time $(\mathrm{h})$, and $\mathrm{U}=$ percentage of asNDFom indigestible in buffered rumen fluid. Regression models were fitted using options BEST $=10$ and $\mathrm{METHOD}=$ Marquardt. Discrete lag time (L) was defined as the time interval required before disappearance of fraction B began. Furthermore, whenever $\mathrm{L}>\mathrm{T}$, asNDFom $\mathrm{REM}_{\mathrm{T}}$ was constrained to $\mathrm{B}+\mathrm{U}$. Although forage fiber is generally assumed to be insoluble in water and has been used successfully as an internal marker to measure DM losses in rain-damaged hays (Scarbrough et al., 2005), numerous in situ studies (Hoffman et al., 1993; Flores et al., 2007) have observed that NDF is not completely recovered in response to rinsing or wetting (without ruminal incubation) at $\mathrm{T}=$ $0 \mathrm{~h}$, and this occurrence often is associated with immature cool-season grasses (Hoffman et al., 1993). When this situation occurs, this percentage of forage fiber is often explained as minute particle loss (Flores et al., 2007 ) and is designated as fraction $\mathrm{A}$, where: $\mathrm{A}=100 \%$ $-(\mathrm{B}+\mathrm{U})$. For the present study, this concept was applied to the $2 \mathrm{P}$ analysis to account for asNDFom not included in $\mathrm{B}$ and $\mathrm{U}$ pools at $\mathrm{T}=0$ (y-intercept). For the $2 \mathrm{P}$ model, $\mathrm{U}$ was determined directly by nonlinear regression (Mertens and Loften, 1980) without any constraint on incubation time and, although very similar, was not directly equated to the asNDFom remaining after a 240-h incubation.

For the $3 \mathrm{P}$ model, fraction $\mathrm{B}$ was subdivided into fast (Bfast) and slow (Bslow) pools with corresponding rate constants calculated for each $\mathrm{B}$ subfraction ( $\mathbf{K}_{\mathrm{d}}$ fast and $\mathbf{K}_{\mathrm{d}}$ slow, respectively). The PROC NLIN of SAS (SAS Institute Inc.) with options BEST $=10$ and METHOD = Marquardt again was used to fit the nonlinear regression model:

$$
\begin{aligned}
& \left.\operatorname{asNDFom~REM}_{\mathrm{T}}=\left\{\text { Bfast } \times \mathrm{e}^{\left[-\mathrm{K}_{\mathrm{d}} \text { fast } \times(\mathrm{T}-\mathrm{L})\right.}\right]\right\} \\
& +\left\{\text { Bslow } \times \mathrm{e}^{\left[-\mathrm{K}_{\mathrm{d}} \text { slow } \times(\mathrm{T}-\mathrm{L})\right]}\right\}+\mathrm{U},
\end{aligned}
$$

An issue with incomplete recovery of asNDFom at $\mathrm{T}=$ 0 for some (mostly immature) forages also was observed for the $3 \mathrm{P}$ model, and a fraction $\mathrm{A}$ was calculated in a manner similar to that described previously $[\mathrm{A}=$ $100 \%-($ Bfast + Bslow + U)]. To limit the number of parameters estimated by PROC NLIN for a relatively complex regression model, 2 procedural compromises were used: (1) a single discrete lag (L) was fit to the data that was applied to both the Bfast and Bslow pools, and (2) fraction $\mathrm{U}$ was not fit by nonlinear regression but rather was determined directly as the percentage of asNDFom remaining after a $240-\mathrm{h}$ incubation. Discrete lag time $(\mathrm{L})$ was defined as the time interval before disappearance of Bfast and Bslow pools began and was assumed to be the same for both B pools, thereby aiding and simplifying model convergence. A modified 3-pool (M3P) model also was evaluated, primarily to circumvent issues related to incomplete recovery of asNDFom at the y-intercept $(\mathrm{T}=0 \mathrm{~h})$ for forages harvested at immature growth stages. For the M3P, the $3 \mathrm{P}$ regression model was modified by forcing the $y$-intercept through $100 \%$ by including a theoretical point $(\mathrm{x}=0 \mathrm{~h}, \mathrm{y}=$ $100 \%$ of asNDFom) in the data set for each forage. To aid model convergence after setting the y-intercept to $100 \%$ of asNDFom, individual observations where $\mathrm{T}<$ $\mathrm{L}$ also were deleted from the data set.

2017 Harvest. In contrast to the kinetic evaluations conducted for forages harvested during 2016, triticale forages from 2017 were evaluated for single endpoints only after in vitro incubations of $24,30,48$, and $240 \mathrm{~h}$. Each of the 24 plot samples was evaluated in triplicate, where incubation jars containing each of the triplicate evaluations were assigned to a different position within the Daisy II incubator system and the temperature of each incubator box was standardized to $39^{\circ} \mathrm{C}$ with an independent thermometer. Rumen fluid was drawn from 2 nonlactating Holstein cows offered a forage-based diet for ad libitum daily intake. The diet included alfalfa-grass haylage (84.7\%), corn silage (13.3\%), and minerals (2.0\%); the nutritional composition of the diet was $\mathrm{NDF}=55.0 \%, \mathrm{CP}=10.1 \%$, and $\mathrm{TDN}=58.1 \%$ (University of Wisconsin Soil and Forage Laboratory, Marshfield, WI). Other aspects of in vitro procedures were consistent with those described for forages harvested the previous year.

\section{Statistics}

2016 Harvest. For all response variables, means and standard deviations were calculated and reported for 5 field replications on each harvest date by PROC MEANS of SAS (SAS Institute Inc.). Response variables were regressed against growth stage or GDD accumulated since January 1 by PROC REG of SAS (SAS Institute Inc.) using linear, quadratic, cubic, and quartic models. Identification of the most appropriate polynomial model was based on a significant $(P$ 
Table 1. Summary of harvest dates, growth stages, accumulated growing degree days $>5^{\circ} \mathrm{C}$, and initial concentrations of asNDFom for triticale forages harvested at Marshfield, Wisconsin, during 2016

\begin{tabular}{|c|c|c|c|c|c|}
\hline \multirow[b]{2}{*}{$\begin{array}{l}\text { Harvest } \\
\text { date }\end{array}$} & \multirow{2}{*}{$\begin{array}{l}\text { Descriptive } \\
\text { growth stage }\end{array}$} & \multirow[b]{2}{*}{$\mathrm{GDD}^{1}$} & \multirow{2}{*}{$\begin{array}{c}\text { Mean } \\
\text { growth stage }^{2}\end{array}$} & \multicolumn{2}{|c|}{ asNDFom, ${ }^{3} \%$ of DM } \\
\hline & & & & Mean $^{4}$ & $\mathrm{SD}^{4}$ \\
\hline May 19 & Elongation & 220 & 32 & 38.8 & 0.83 \\
\hline May 25 & Boot & 300 & 43 & 47.3 & 1.30 \\
\hline May 31 & Heading & 388 & 52 & 58.9 & 0.77 \\
\hline June 9 & Anthesis & 489 & 66 & 65.0 & 2.04 \\
\hline July 1 & Soft dough & 817 & 84 & 54.5 & 1.99 \\
\hline
\end{tabular}

${ }^{1}$ Growing degree days $>5^{\circ} \mathrm{C}$ accumulated from January 1 (Coblentz et al., 2018).

${ }^{2}$ Stage of growth identified as tillering (20-29), stem elongation (30-39), booting (40-49), heading (50-59), anthesis (60-69), seed development (70-79), and seed ripening (80-89; Stauss, 1994).

${ }^{3}$ Concentration of NDF determined with sodium sulfite and heat-stable $\alpha$-amylase and then corrected for residual ash.

${ }^{4}$ Based on 5 field replications on each harvest date for 2016 .

$<0.05)$ coefficient for each polynomial order coupled with the greatest possible coefficient of determination $\left(\mathrm{R}^{2}\right)$. To avoid overfitting, higher-ordered models were not considered when there was no obvious physiological explanation for the complex character of the curve. Intercepts were retained in all models irrespective of whether they differed $(P<0.05)$ from 0 .

For triticale forages harvested during 2016, singleendpoint determinations of NDFD at commonly used endpoints $(24,30$, or $48 \mathrm{~h})$ were determined from the 3 in vitro decay models $(2 \mathrm{P}, 3 \mathrm{P}$, and $\mathrm{M} 3 \mathrm{P})$ and subjected to ANOVA based on a randomized complete block design with a $3 \times 5$ factorial arrangement of treatments that included 5 field blocks, 3 decay models, and 5 harvest dates. Single-endpoint estimates of NDFD were then regressed on growth stage and GDD as described previously.

2017 Harvest. Triplicate determinations of NDFD after 24-, 30-, 48-, and 240-h in vitro incubations in buffered rumen fluid were averaged before any subsequent analysis. Fraction U was calculated as the percentage of asNDFom remaining after a $240-\mathrm{h}$ in vitro incubation. Means and standard deviations for each forage harvest date were calculated and reported for 4 field replications by PROC MEANS of SAS (SAS Institute Inc.). Fraction $U$ as well as NDFD following incubations of 24,30 , or $48 \mathrm{~h}$ were regressed against growth stage or GDD accumulated since January 1 by PROC REG of SAS (SAS Institute Inc.) using linear, quadratic, cubic, and quartic models as described previously.

\section{RESULTS AND DISCUSSION}

\section{Concentrations of asNDFom (2016 Harvest)}

Harvest dates, GDD, and the mean growth stage and concentration of asNDFom on each harvest date during 2016 are summarized in Table 1. Mean concentrations of asNDFom ranged from $38.8 \%$ at stem elongation to $65.0 \%$ at the anthesis stage of growth. A 10.5-percentage unit decline occurred between the anthesis and soft dough stages of growth, which was directly related to the dilution of asNDFom by the physiological process of grain fill. All other indices of nutritive value are described and discussed in detail in a companion report (Coblentz et al., 2018).

\section{P Model (2016 Harvest)}

Fractions $\boldsymbol{A}, \boldsymbol{B}$, and $\boldsymbol{U}$. Fraction A on each harvest date (Table 2) was greatest during stem elongation $(14.5 \%)$ but then declined to near negligible percentages of asNDFom $(\leq 2.2 \%)$ after forages reached the heading stage of growth. The regression of A on growth stage was best fit to a quadratic model $(P<0.001$; Figure 1) that explained approximately $90 \%$ of the variation within the data set $\left(\mathrm{R}^{2}=0.896\right)$. Fraction B also exhibited a quadratic $(P<0.001)$ relationship with plant growth stage that was effective $\left(\mathrm{R}^{2}=0.934\right)$ in explaining a response that was static through the heading stage of growth but then declined thereafter. Fraction B ranged narrowly (mean $=72.2-74.4 \%$; Table 2) across the stem elongation, boot, and heading stages of growth before declining to about half of the total asNDFom pool by the soft dough stage (mean = $52.9 \%$ ). Unlike A and B, fraction U increased linearly $(P<0.001)$ with growth stage, exhibiting little variability around the regression relationship $\left(\mathrm{R}^{2}=0.979\right)$. As expected, the mean percentage of indigestible asNDFom was least for plants during stem elongation $($ mean $=13.4 \%$; Table 2$)$ but increased to almost half (mean $=46.9 \%)$ of the total asNDFom pool at the soft dough stage of growth. Based on initial concentrations of asNDFom, $\mathrm{U}$ determined by $2 \mathrm{P}$ would represent 5.2 , $8.2,15.1,22.6$, and $25.6 \%$ of the total forage DM at 
Table 2. Regression parameters for in vitro disappearance of asNDFom ${ }^{1}$ as determined by a 2-pool model ${ }^{2}$ for triticale forages harvested at Marshfield, Wisconsin, during May through July 2016

\begin{tabular}{|c|c|c|c|c|c|c|c|c|c|c|c|}
\hline \multirow{2}{*}{$\begin{array}{l}\text { Harvest } \\
\text { date }\end{array}$} & \multirow{2}{*}{$\begin{array}{l}\text { Descriptive } \\
\text { growth stage }\end{array}$} & \multicolumn{6}{|c|}{ asNDFom fraction, ${ }^{3} \%$ of asNDFom } & & & & \\
\hline & & \multicolumn{2}{|c|}{$\mathrm{A}$} & \multicolumn{2}{|c|}{ B } & \multicolumn{2}{|c|}{$\mathrm{U}$} & \multicolumn{2}{|c|}{$\mathrm{K}_{\mathrm{d}}, / \mathrm{h}$} & \multicolumn{2}{|c|}{ Lag, h } \\
\hline May 19 & Elongation & 14.5 & 1.91 & 72.2 & 2.24 & 13.4 & 0.56 & 0.078 & 0.0062 & 7.34 & 0.020 \\
\hline May 25 & Boot & 8.2 & 1.54 & 74.4 & 1.60 & 17.4 & 1.32 & 0.059 & 0.0042 & 7.38 & 0.302 \\
\hline May 31 & Heading & 2.2 & 1.82 & 72.2 & 2.34 & 25.6 & 0.63 & 0.046 & 0.0039 & 5.85 & 0.613 \\
\hline
\end{tabular}

${ }^{1}$ Concentration of NDF in triticale forages as determined with heat-stable $\alpha$-amylase and sodium sulfite and corrected further by removing residual ash.

${ }^{2}$ All asNDFom fractions, disappearance rate $\left(\mathrm{K}_{\mathrm{d}}\right)$, and discrete lag time were determined by nonlinear regression, where asNDFom remaining $\left.=\left\{\mathrm{B} \times \mathrm{e}^{\left[-\mathrm{K}_{\mathrm{d}} \times(\text { incubation time }-\mathrm{lag})\right.}\right]\right\}+\mathrm{U}$.

${ }^{3}$ Fraction A represents the pool of asNDFom disappearing at a rate too fast to measure, and was determined from the $\mathrm{y}$-intercept, where $\mathrm{A}=$ $100 \%-(B+U)$. Fraction B is the pool of asNDFom that disappears at a measurable rate, and $U=$ indigestible asNDFom as determined from the nonlinear regression model.

${ }^{4}$ Based on 5 field replications.

the stem elongation, boot, heading, anthesis, and soft dough stages of growth, respectively.

$K_{d}$ and Discrete Lag Time. Mean rates of asNDFom disappearance from fiber bags ranged from 0.078 to $0.031 / \mathrm{h}$ (Table 2 ), which equates to a $60.3 \%$ decline in $K_{d}$ between the stem elongation and soft dough stages of growth. The regression of $\mathrm{K}_{\mathrm{d}}$ derived from individual field plots on growth stage (Figure 2) was best fitted to a close quadratic relationship $(P<0.001$; $\left.\mathrm{R}^{2}=0.943\right)$ in which $\mathrm{K}_{\mathrm{d}}$ declined most rapidly between

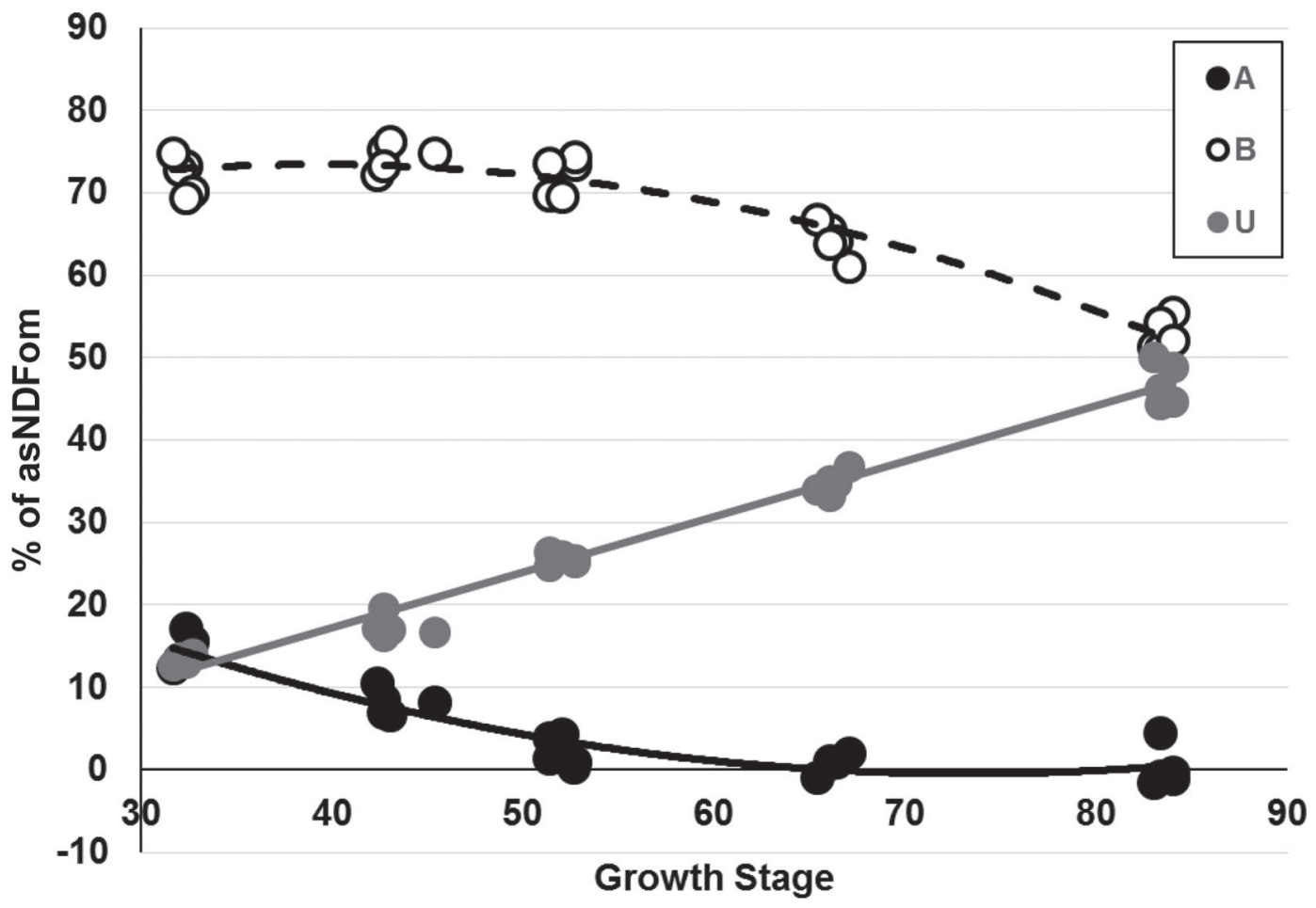

Figure 1. Regressions of fractions A, B, and U derived from a traditional 2-pool model for in vitro asNDFom disappearance on growth stage for triticale forages harvested during 2016 at Marshfield, Wisconsin. Equations were as follows: A ( $\%$ of asNDFom) $=0.00882 \mathrm{x}^{2}-1.29 \mathrm{x}+46.9$, $\mathrm{R}^{2}=0.896$, root mean squared error $(\mathrm{RMSE})=1.95 \% ; \mathrm{B}(\%$ of asNDFom $)=-0.0107 \mathrm{x}^{2}+0.840 \mathrm{x}+57.0, \mathrm{R}^{2}=0.934, \mathrm{RMSE}=2.23 \%$; and $\mathrm{U}$ $(\%$ of asNDFom $)=0.672 \mathrm{x}-9.6, \mathrm{R}^{2}=0.979, \mathrm{RMSE}=1.84 \%$. Fraction A represents the pool of asNDFom disappearing at a rate too fast to measure, fraction $\mathrm{B}$ disappears at a measurable rate, and fraction $\mathrm{U}$ is indigestible in buffered rumen fluid. 


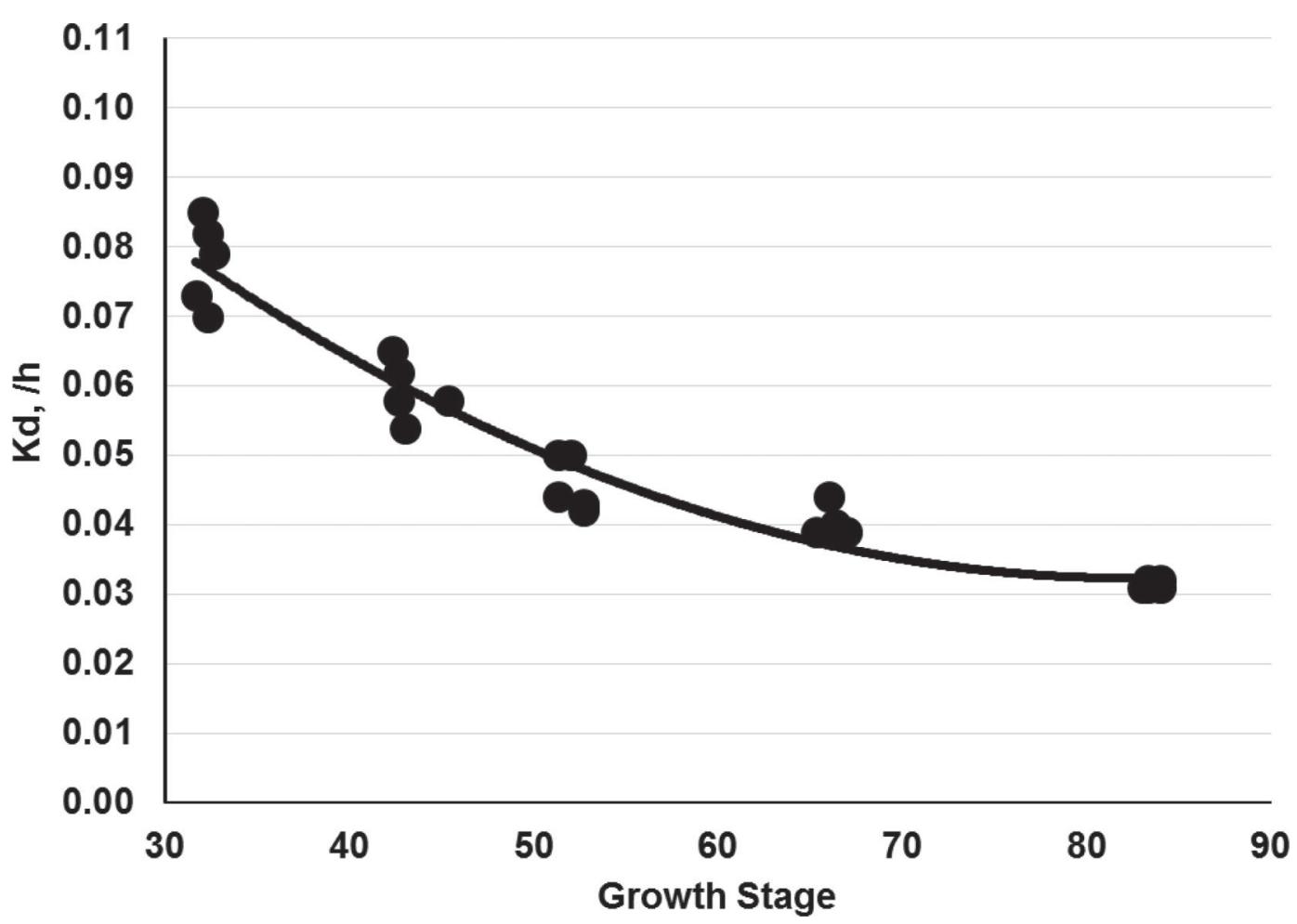

Figure 2. In vitro disappearance rates $\left(\mathrm{K}_{\mathrm{d}}\right)$ of asNDFom regressed on growth stage for $(\mathrm{n}=25)$ triticale forages harvested during 2016 in Marshfield, Wisconsin. Disappearance rates were determined by a traditional 2-pool nonlinear model. The regression equation was $\mathrm{K}_{\mathrm{d}}(/ \mathrm{h})=$ $0.0000177 \mathrm{x}^{2}-0.00292 \mathrm{x}+0.153, \mathrm{R}^{2}=0.943$, root mean squared error $=0.0042 / \mathrm{h}$.

the stem elongation and heading stages of growth before stabilizing thereafter. The range of mean discrete $\mathrm{L}$ across growth stages was only $1.53 \mathrm{~h}($ mean $=5.85-7.38$ $\mathrm{h}$; Table 2), and unlike the other kinetic parameters described for the $2 \mathrm{P}$ model, $\mathrm{L}$ exhibited a poor relationship $\left(\mathrm{L}=0.00129 \mathrm{x}^{2}-0.161 \mathrm{x}+11.33 ; \mathrm{R}^{2}=0.307 ; P\right.$ $=0.018)$ with growth stage that was best fitted to a quadratic model (data not shown).

\section{P Model (2016 Harvest)}

Fractions A, Bfast, Bslow, and U. When asNDFom disappearance data were fitted to the $3 \mathrm{P}$ decay model, fractions A and U (Table 3) varied only minimally from those discussed for the 2P model. Similarly, regressions of these fractions on growth stage (Figure 3 ) yielded the most appropriate models of the same polynomial order and with similar coefficients of determination $\left(\mathrm{R}^{2} \geq 0.899\right)$ as those described for the $2 \mathrm{P}$ analysis. For these fractions, the primary discrepancy between the $2 \mathrm{P}$ and $3 \mathrm{P}$ models was that $\mathrm{U}$ was consistently less when determined directly from a 240 -h incubation in the $3 \mathrm{P}$ analysis compared with $2 \mathrm{P}$ procedures. For $2 \mathrm{P}$ procedures, U was fitted directly by nonlinear regression as described by Mertens and Loften (1980), with no restraint on the incubation time at which the disap- pearance of asNDFom becomes asymptotic. In practical terms, this discrepancy was small, ranging from 1.8 to 3.2 percentage units for means on specific harvest dates, which also was corroborated by a difference of similar magnitude for respective intercepts calculated for the $2 \mathrm{P}$ and $3 \mathrm{P}$ linear regression models on growth stage ( -9.6 vs. $-11.1 \%)$. Based on our curve-fitting experiences for the $3 \mathrm{P}$ model, fitting $\mathrm{U}$ directly by nonlinear regression was problematic, in part because of the greater number of parameters to be estimated in these complex models. As such, direct estimation of $\mathrm{U}$ by nonlinear regression within a $3 \mathrm{P}$ model for these triticale forages presented consistent problems with convergence or spurious estimates of regression parameters and is probably not reliable on a practical basis. To eliminate the discrepancy between U observed for the $2 \mathrm{P}$ model compared with the $3 \mathrm{P}$ model, the simplest approach would be to arbitrarily set or define $\mathrm{U}$ to be the percentage of asNDFom remaining after a 240-h incubation, even when calculating $2 \mathrm{P}$ kinetics.

The overall mean fraction $U$ for triticale forages (25.1\% of asNDFom) compares closely with a mean value for unspecified grasses $(21.1 \%)$ reported by Raffrenato and Van Amburgh (2010), but our overall range (11.6-44.3\%) overlaps the mean values for brown midrib corn silage (13.1\%), conventional corn silage (20.6\%), 
NEUTRAL DETERGENT FIBER DIGESTIBILITY OF TRITICALE FORAGES

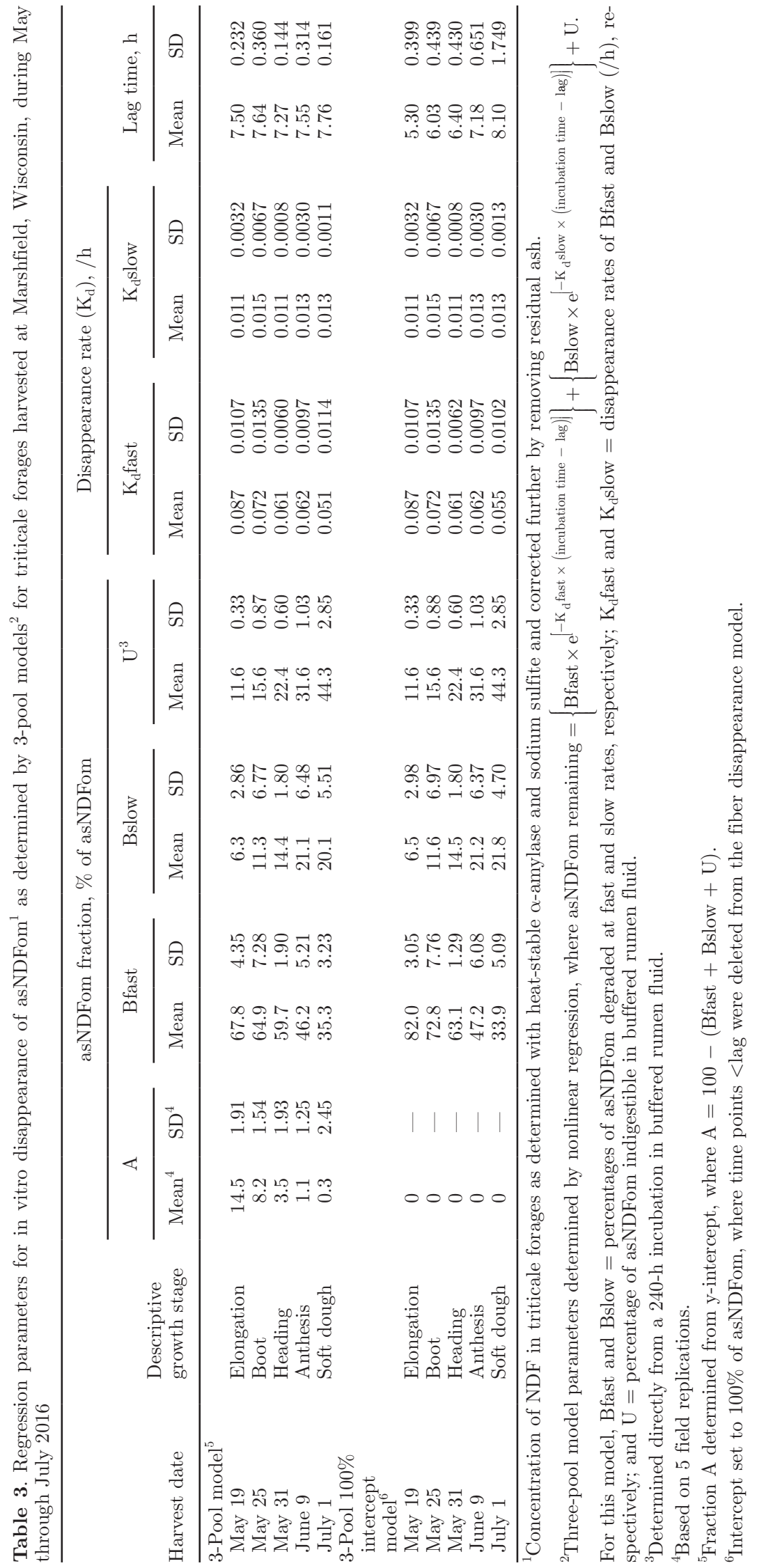


and alfalfa (42.5\%) also reported by Raffrenato and Van Amburgh (2010). While our direct determinations of U predictably increased with plant maturity, they were substantially greater than corresponding estimates of $\mathrm{U}$ calculated using $[(2.4 \times \mathrm{ADL}) / \mathrm{asNDFom}]$ $\times 100 \%$ (Chandler et al., 1980) that ranged from 7.2 to $20.0 \%$ of asNDFom. Similarly, they also exceeded those calculated by the approach identified in NRC (2001), where $\mathrm{U}=(\mathrm{ADL} / \mathrm{asNDFom})^{0.667}$, and ranged from 9.6 to $19.1 \%$ of asNDFom. Some studies have chosen to reinoculate digestion vessels when incubation times exceed 120 h (Raffrenato and Van Amburgh, 2010). It remains unclear how reinoculation might affect fraction U determined in the Daisy II incubator system, but this option may be worthy of investigation in further studies. Based on our initial concentrations of asNDFom (Table 1), fraction U determined from a 240-h incubation would represent $4.5,7.4,13.2,20.5$, and $24.1 \%$ of the total forage DM at the stem elongation, boot, heading, anthesis, and soft dough stages of growth, respectively. Therefore, for a $680-\mathrm{kg}$ cow consuming 27.2 $\mathrm{kg}$ of DM (4\% of BW) of a TMR daily containing $15 \%$ triticale silage harvested at boot stage, the daily intake of U from triticale silage would be about $300 \mathrm{~g}$. Grant (2015) described fraction U as a baseline of ruminal fill that constrains possible NDF flux; within this concept, a minimum pool is required to maintain proper rumen function, but exceeding an upper threshold may limit voluntary intake. Furthermore, it was suggested that daily intake of indigestible asNDFom by high-producing cows typically ranges from 0.30 to $0.48 \%$ of BW. Using the previous example, inclusion of boot-stage triticale at a rate of $15 \%$ of the total diet would account for 9 to $15 \%$ of this range.

Subdividing B into fast and slow pools resulted in inverse responses for the 2 pools across harvest dates. The mean Bfast for specific harvest dates declined from 67.8 to $35.3 \%$ of the total asNDFom pool between the stem elongation and soft dough stages of growth (Table 3 ). Across the same progression of growth stages, Bslow increased from 6.3 to $20.1 \%$, which means the slow pool accounted for $8.5 \%$ of the combined B pool during stem elongation but $36.3 \%$ at the soft dough stage of growth. Regressions of Bfast and Bslow on growth stage were simplified compared with the quadratic relationship detected in the $2 \mathrm{P}$ analysis. Both $\mathrm{B}$ subfractions were

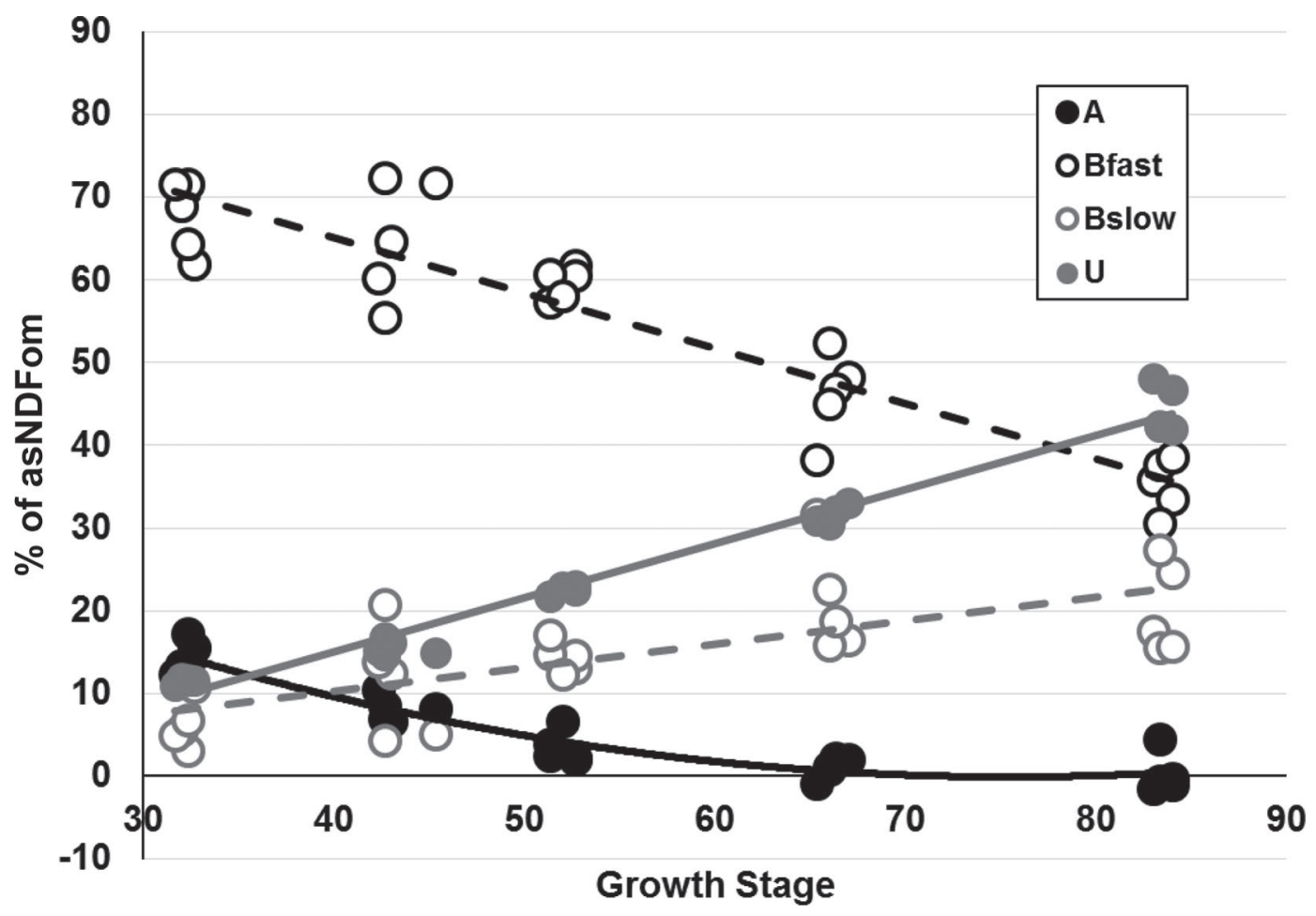

Figure 3. Regression relationships between various asNDFom fractions derived from a 3-pool model for in vitro asNDFom disappearance on growth stage for $(\mathrm{n}=25)$ triticale forages harvested in 2016 at Marshfield, Wisconsin. For this application, fraction A represents asNDFom unaccounted for by the Bfast, Bslow, and U pools, where Bfast and Bslow are pools of asNDFom disappearing at fast and slow rates, respectively, and $\mathrm{U}$ is indigestible in buffered rumen fluid. Equations are defined as follows: A ( $\%$ of asNDFom) $=0.00770 \mathrm{x}^{2}-1.16 \mathrm{x}+43.8, \mathrm{R}^{2}=0.899$, root mean squared error $(\mathrm{RMSE})=1.86 \%$; Bfast $(\%$ of asNDFom $)=-0.669 \mathrm{x}+91.8, \mathrm{R}^{2}=0.858, \mathrm{RMSE}=5.08 \%$; Bslow $(\%$ of asNDFom $)=$ $0.282 \mathrm{x}-1.0, \mathrm{R}^{2}=0.499, \mathrm{RMSE}=5.29 \% ;$ and $\mathrm{U}(\%$ of asNDFom $)=0.654 \mathrm{x}-11.1, \mathrm{R}^{2}=0.979, \mathrm{RMSE}=1.80 \%$. 
related to growth stage by a linear model $(P<0.001$; Figure 3) describing respective decreasing and increasing trends with plant maturity; however, the coefficient of determination for Bfast $\left(\mathrm{R}^{2}=0.858\right)$ indicated substantially better fit than observed for Bslow $\left(\mathrm{R}^{2}=\right.$ 0.499).

$K_{d}$ fast, $K_{d}$ slow, and Lag Time. Mean disappearance rates calculated for the Bfast pool ranged from 0.087 to $0.051 / \mathrm{h}$ (Table 3 ), thereby representing a $41.4 \%$ reduction between the stem elongation and soft dough stages of growth. The regression of $\mathrm{K}_{\mathrm{d}}$ fast on growth stage yielded a simple linear $(P<0.001)$ model that explained more than half $\left(\mathrm{R}^{2}=0.555\right)$ of the variability within the data set (Figure 4). Perhaps predictably, estimates of $K_{d}$ fast on specific harvest dates were consistently faster than observed for the combined $\mathrm{B}$ pool within the $2 \mathrm{P}$ analysis, with specific differentials between the 2 modeling approaches ranging narrowly from 0.015 to $0.022 / \mathrm{h}$. Unlike $\mathrm{K}_{\mathrm{d}}$ fast, mean disappearance rates for $\mathrm{K}_{\mathrm{d}}$ slow ranged narrowly from 0.011 to $0.015 / \mathrm{h}$ on specific harvest dates, and regressions of $\mathrm{K}_{\mathrm{d}}$ slow on growth stage detected no significant $(P \geq$ 0.269) linear, quadratic, cubic, or quartic model. Similarly, no polynomial model was significant $(P \geq 0.064)$ for the regression of discrete $\mathrm{L}$ on growth stage, where mean $=7.54 \mathrm{~h}$ (Table 3$)$. The relationship between $\mathrm{K}_{\mathrm{d}}$ fast and $K_{d}$ slow observed for triticale forages was similar to that reported by Raffrenato and Van Amburgh (2010), in which grasses (species not stated) exhibited a relatively rapid $\mathrm{K}_{\mathrm{d}}$ fast $(0.094 / \mathrm{h})$ but a slow $\mathrm{K}_{\mathrm{d}}$ slow $(0.016 / \mathrm{h})$. The unique observation of our triticale data is that $\mathrm{K}_{\mathrm{d}}$ slow was very slow $($ mean $=0.013 / \mathrm{h}$ ), ranged narrowly across all forages, and could not be related to growth stage by any of the polynomial regression models evaluated. This occurred despite very clear increases in Bslow as triticale plants matured.

\section{M3P Model (2016 Harvest)}

Fractions Bfast, Bslow, and $U$. Inclusion of a theoretical point representing $100 \%$ of asNDFom at $\mathrm{T}$ $=0 \mathrm{~h}$ was effective at allowing complete statistical recovery of the total asNDFom pool within Bfast, Bslow, and $U$ fractions (Table 3). To aid convergence of the model, it was necessary to eliminate points where L $>\mathrm{T}$, thereby avoiding an additional early inflection point, which was mostly necessary for forages harvested during stem elongation or at boot stage. With only minor inconsistencies, these procedural modifications effectively consolidated pools A and Bfast derived from

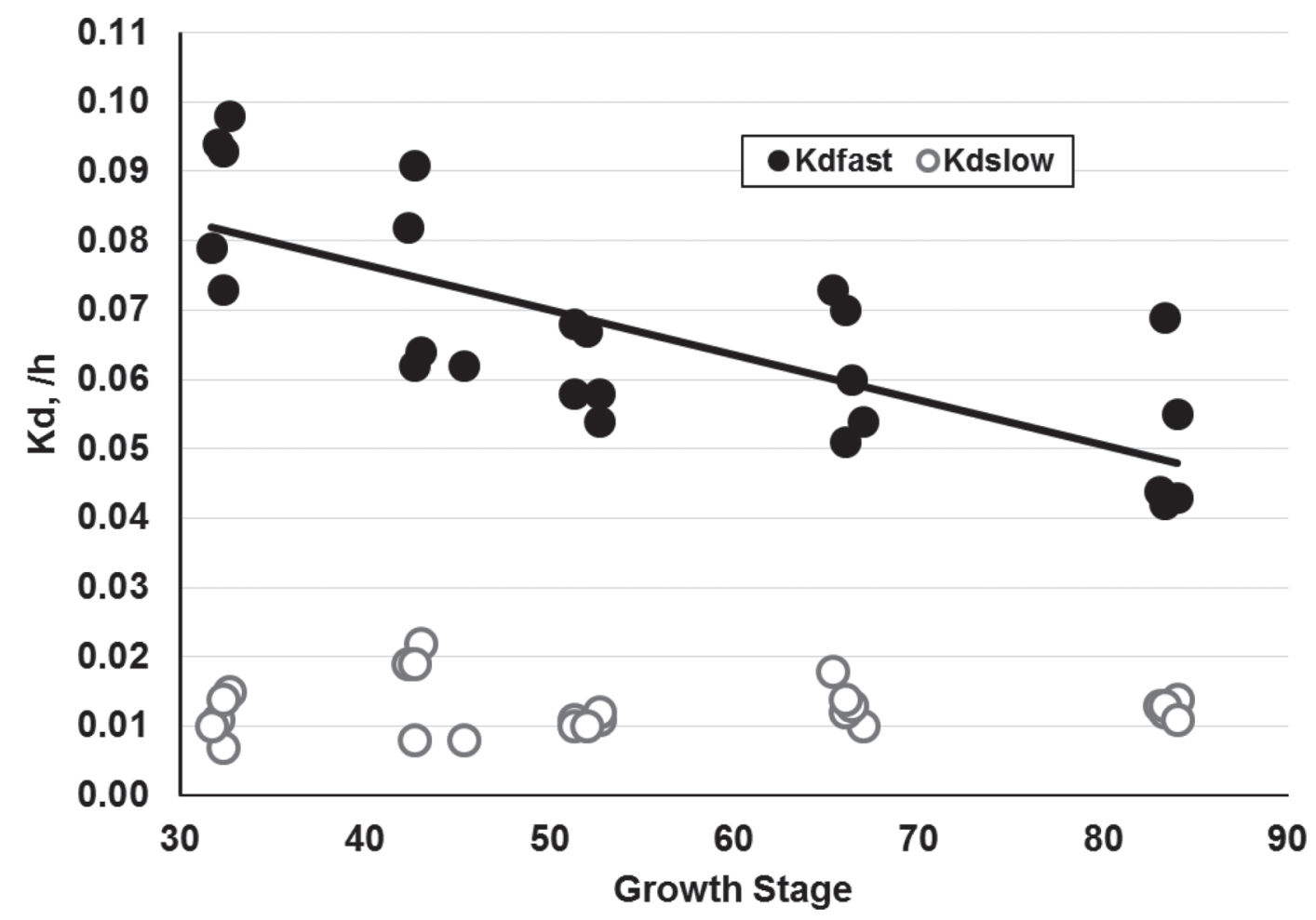

Figure 4. Regression relationships for in vitro disappearance rates of fast ( $\mathrm{K}_{\mathrm{d}}$ fast) and slow $\left(\mathrm{K}_{\mathrm{d}} \mathrm{slow}\right)$ pools of asNDFom on growth stage for $(\mathrm{n}=25)$ triticale forages harvested during 2016 at Marshfield, Wisconsin. Figure represents rate estimates derived from the 3-pool model, where $\mathrm{K}_{\mathrm{d}}$ fast $=-0.000651 \mathrm{x}+0.103, \mathrm{R}^{2}=0.555$, root mean squared error $=0.0109 / \mathrm{h}$. For $\mathrm{K}_{\mathrm{d}}$ slow, quartic, cubic, quadratic, and linear regressions were not significant for the 3 -pool model $(P \geq 0.269$; mean $=0.013 / \mathrm{h})$, suggesting no relationship between $\mathrm{K}_{\mathrm{d}}$ slow and growth stage. 
the $3 \mathrm{P}$ model into a single Bfast pool for the M3P approach. Furthermore, Bslow varied only minimally from that described previously for the $3 \mathrm{P}$ model, whereas $\mathrm{U}$ was identical between $3 \mathrm{P}$ models because it was determined experimentally and fixed as such. Regressions of Bfast and Bslow on growth stage (Figure 5) yielded best fits with simple linear $(P<0.001)$ models; for Bslow, slopes and intercepts varied only minimally between $3 \mathrm{P}$ (Bslow $=0.282 \mathrm{x}-1.0$ ) and M3P (Bslow $=0.307 \mathrm{x}-1.9)$ regression procedures, and respective coefficients of determination $\left(\mathrm{R}^{2}=0.449\right.$ and 0.565$)$ were poorer than observed for Bfast and most other regression parameters. Although Bfast derived from M3P was best explained by a linear regression model, the greater slope and intercept (Bfast $=-0.960 \mathrm{x}+$ 113.0) further reflect the consolidation of $\mathrm{A}$ and Bfast pools relative to the $3 \mathrm{P}$ regression procedures described previously.

$K_{d}$ fast, $K_{d}$ slow, and Lag Time. Although mean estimates of $\mathrm{K}_{\mathrm{d}}$ fast for individual harvest dates differed only minimally between the $3 \mathrm{P}$ regression approaches (Table 3 ), the regression of $\mathrm{K}_{\mathrm{d}}$ fast derived from individual plots on growth stage was best fitted to a quadratic model (Figure 6), which differed from the linear fit selected for 3P decay of asNDFom. Mostly, this was the consequence of marginally increased estimates of $K_{d}$ fast at the soft dough stage of growth. As observed for the $3 \mathrm{P}$ decay procedures, $\mathrm{K}_{\mathrm{d}}$ slow could not be related to growth stage by linear, quadratic, cubic, or quartic models (mean $=0.013 / \mathrm{h} ; P \geq 0.249$ ). One unique result of the M3P approach was a clear increasing trend in $\mathrm{L}$ as triticale plants matured; mean estimates of L increased from 5.30 to $8.10 \mathrm{~h}$ between the stem elongation and soft dough stages of growth, respectively (Table 3 ). Regression of $\mathrm{L}$ from individual plots on growth stage $\left(\mathrm{L}=0.0534 \mathrm{x}+3.64 ; \mathrm{R}^{2}=0.583\right.$; $P<0.001)$ yielded a linear relationship with an intermediate coefficient of determination (data not shown). Much of the lack of fit was associated with the soft dough stage of growth, where the standard deviation $(1.749 \mathrm{~h})$ across plots was 2.7 to 4.4 times greater than other growth stages (Table 3 ).

\section{Comments on Fitting 3P and M3P Models}

Fitting in vitro disappearance of asNDFom to $3 \mathrm{P}$ models proved to be a relatively straightforward process but with a couple of caveats. To simplify conver-

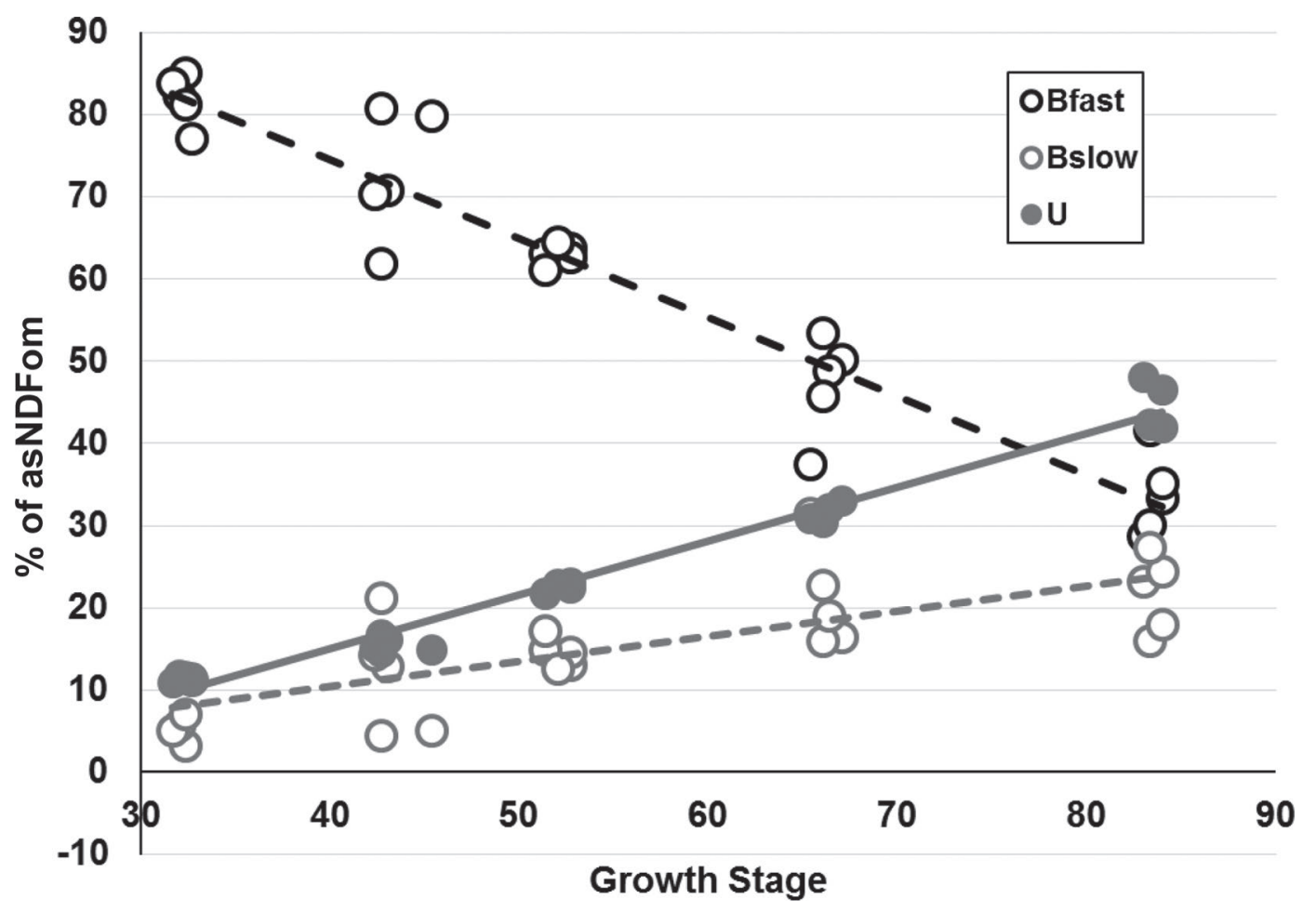

Figure 5. Regression relationships between various asNDFom fractions derived from a modified 3-pool model of in vitro disappearance on growth stage for $(\mathrm{n}=25)$ triticale forages harvested in 2016 at Marshfield, Wisconsin. Equations are as follows: Bfast $(\%$ of asNDFom $)=$ $-0.960 \mathrm{x}+113.0, \mathrm{R}^{2}=0.920$, root mean squared error $(\mathrm{RMSE})=5.29 \%$; Bslow $(\%$ of asNDFom $)=0.307 \mathrm{x}-1.9, \mathrm{R}^{2}=0.565, \mathrm{RMSE}=5.03 \%$; and $\mathrm{U}(\%$ of asNDFom $)=0.654 \mathrm{x}-11.1, \mathrm{R}^{2}=0.979, \mathrm{RMSE}=1.80 \%$. For this model, Bfast and Bslow are pools of asNDFom disappearing at fast and slow rates, respectively, and $U$ is indigestible in buffered rumen fluid. 
gence, 2 compromises were identified that likely will improve the utility of using $3 \mathrm{P}$ models of fiber disappearance, primarily by reducing the number of regression parameters to be estimated. First, a single value of $\mathrm{L}$ was estimated that was assumed to be common to both the Bfast and Bslow pools; it remains unclear whether this assumption is legitimate, but it is likely to be essential to ensure model convergence or avoid nonsensical parameter estimates. Second, when the selection of incubation intervals includes a 240 -h time point, our experience suggests that equating $U$ directly with asNDFom remaining at $240 \mathrm{~h}$ greatly simplified curve fitting and reduced the frequency of problematic parameter estimates.

Another problem was the incomplete recovery of asNDFom from immature triticale forages. Neither the $3 \mathrm{P}$ nor the M3P approach was entirely satisfactory in overcoming this issue. The $3 \mathrm{P}$ model required creation of an asNDFom pool (A) that has undefined physical and chemical properties but that disappears from fiber bags at a rate too fast to be measured. This problem is not unique, and it has been documented in numerous in situ studies of ruminal fiber disappearance; often, it is associated with the relative immaturity of cool-season forage grasses (Hoffman et al., 1993; Flores et al., 2007; Coblentz and Walgenbach, 2010). However, subsequent calculations of effective ruminal degradability based on competing effects of disappearance rate $\left(\mathrm{K}_{\mathrm{d}}\right)$ and passage rate $(\mathrm{Kp})$ - effective degradability $=\mathrm{A}+\mathrm{B}$ $\times\left[\mathrm{K}_{\mathrm{d}} /\left(\mathrm{K}_{\mathrm{d}}+\mathrm{Kp}\right)\right]$ (Ørskov and McDonald, 1979)often assume A to be part of the rumen-degradable pool. The alternate approach (M3P) was implemented by effectively forcing statistically complete recovery of asNDFom by inserting a theoretical point into the decay model, where $\mathrm{y}=100 \%$ at $\mathrm{x}=0 \mathrm{~h}$; this effectively consolidated $\mathrm{A}$ and Bfast determined from the $3 \mathrm{P}$ approach into Bfast for M3P. Although this modification produced a clear linear increase in $\mathrm{L}$ with plant maturity that was not observed with $3 \mathrm{P}$, it also suggests, based on estimates of $\mathrm{L}$ ranging from 5.30 to $8.10 \mathrm{~h}$, that there was no disappearance of asNDFom from bags containing immature triticale forages after 3or 6-h incubations. This condition was clearly untrue. Regardless, these compromises resulted in little or no difference in estimates of $K_{d}$ fast and $K_{d}$ slow between $3 \mathrm{P}$ and M3P approaches.

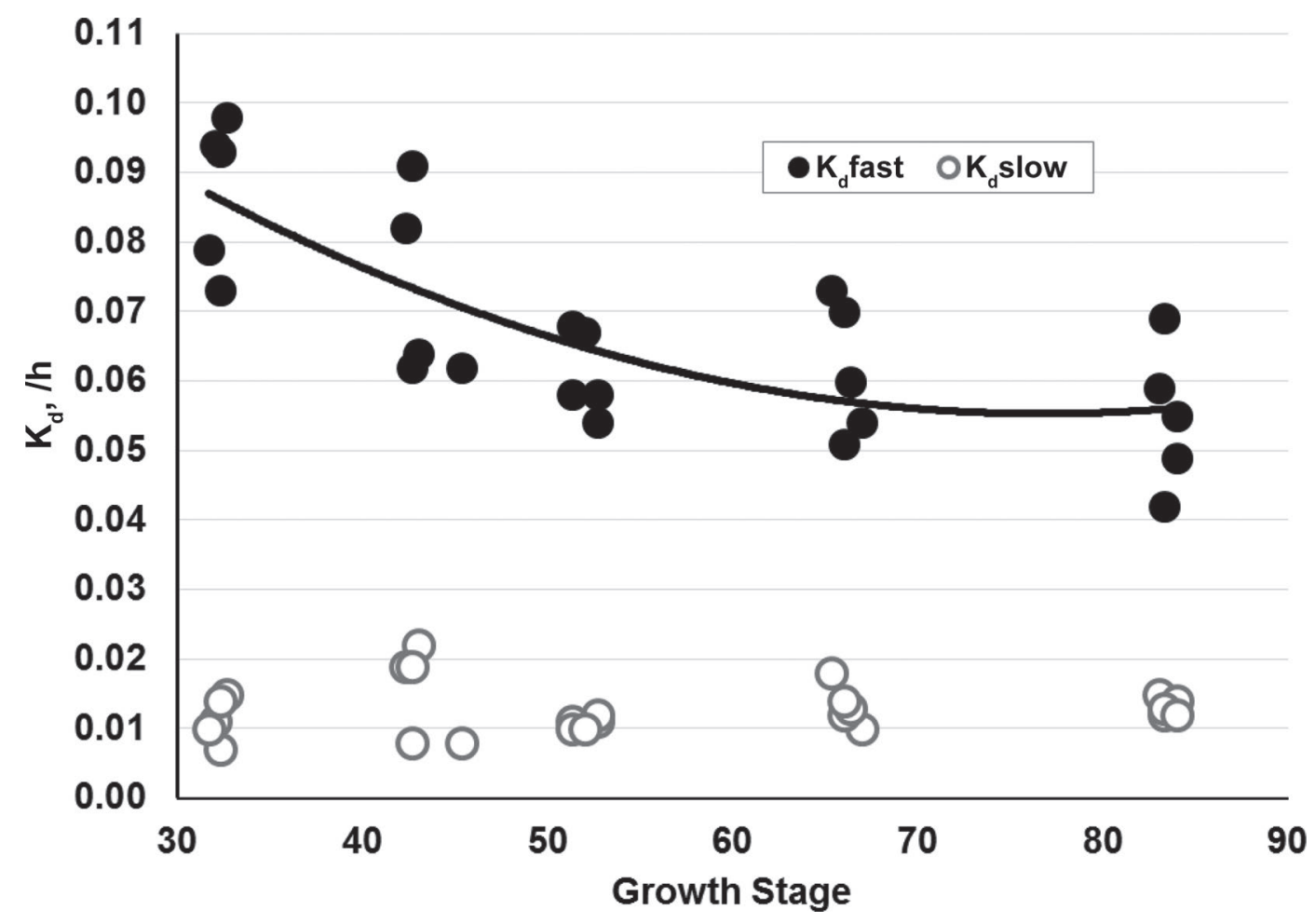

Figure 6. Regression relationship of in vitro disappearance rates for fast $\left(\mathrm{K}_{\mathrm{d}} \mathrm{fast}\right)$ and slow $\left(\mathrm{K}_{\mathrm{d}} \mathrm{slow}\right)$ pools of asNDFom on growth stage for $(\mathrm{n}=25)$ triticale forages harvested during 2016 in Marshfield, Wisconsin. Figure represents rate estimates derived from a modified 3-pool model, where $\mathrm{K}_{\mathrm{d}}$ fast $=0.0000156 \mathrm{x}^{2}-0.00239 \mathrm{x}+0.147, \mathrm{R}^{2}=0.582$, root mean squared error $=0.0101 / \mathrm{h}$. For $\mathrm{K}_{\mathrm{d}}$ slow, quartic, cubic, quadratic, and linear regressions were not significant $(P \geq 0.249)$, suggesting no relationship between $\mathrm{K}_{\mathrm{d}}$ slow and growth stage. 
COBLENTZ ET AL.

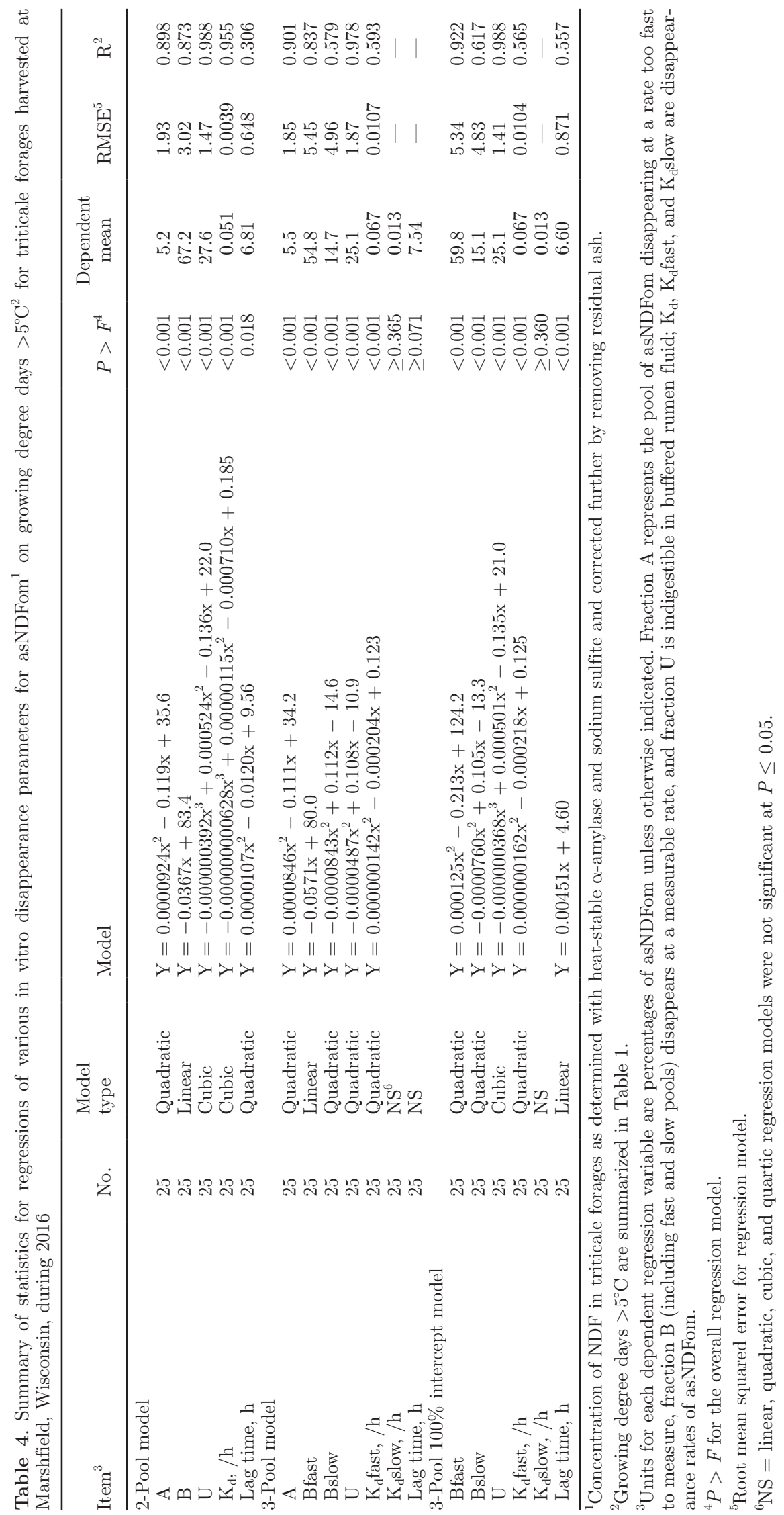




\section{Comments on Regressions of Kinetic Parameters on GDD (2016 Harvest)}

The GDD concept commonly has been used to explain DM yield, nutrient concentration, nutrient yield (uptake), and changes in nutritive value during the normal spring and early summer period of growth for winter-annual cereals (West et al., 1991; Schwarte et al., 2005; Gibson et al., 2007). Although forage producers are far more likely to manage harvest schedules on the basis of a visual assessment of growth stage rather than a running cumulative total of GDD, the use of the
GDD in studies of this type with significant agronomic aspects is somewhat obligatory within a scientific context. It is unclear whether individual kinetic parameters associated with in vitro NDF disappearance from triticale forages have been related to GDD in past work; however, these relationships for 2016 are summarized in Table 4. Because growth stage and GDD are both closely related to time, regressions of kinetic parameters on GDD or growth stage were similar both in terms of the overall shape and nature of the regression response as well as with respect to fit, as determined by coefficient of determination statistics. As observed

Table 5. In vitro neutral detergent fiber disappearance (NDFD; \% of asNDFom ${ }^{1}$ ) based on 24, 30, and 48 h of incubation in buffered rumen fluid for 5 replications of triticale forages harvested in 2016 at Marshfield, Wisconsin ${ }^{2}$

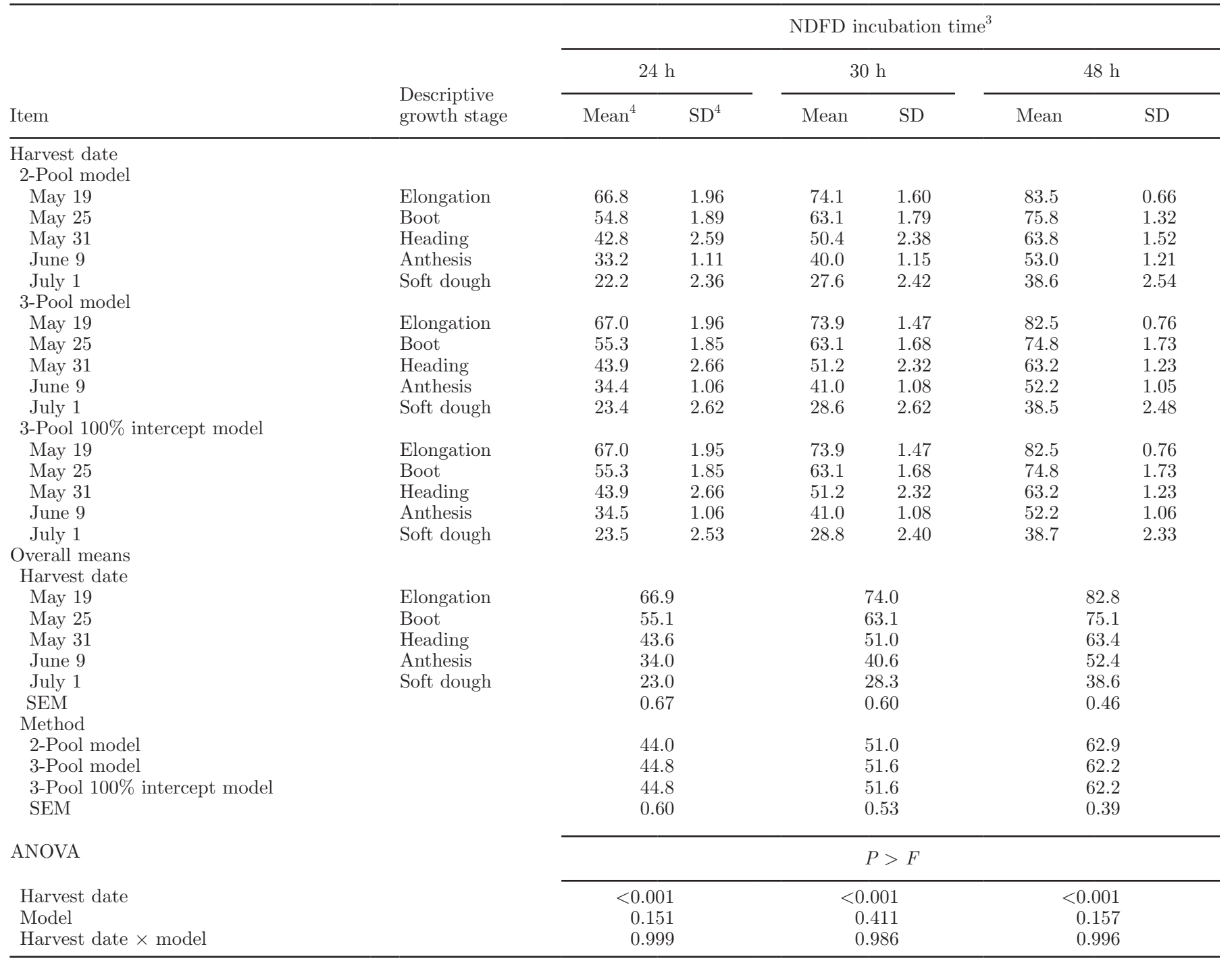

${ }^{1}$ Concentration of NDF in triticale forages as determined with heat-stable $\alpha$-amylase and sodium sulfite and corrected further by removing residual ash.

${ }^{2}$ For each field replication harvested during 2016, NDFD was calculated based on the regression parameters summarized in Tables 2 and 3.

${ }^{3}$ Incubation time in buffered rumen fluid.

${ }^{4}$ Based on 5 field replications. 
for regressions of $K_{d}$ slow on growth stage, regressions on GDD could not be fitted to linear, quadratic, cubic, or quartic models $(P \geq 0.360)$; similarly, no polynomial model explained the relationship between $\mathrm{L}$ determined by the $3 \mathrm{P}$ decay model and GDD $(P \geq 0.071)$.

\section{Single-Endpoint Determinations of NDFD}

2016 Harvest. In vitro asNDFom disappearance (NDFD) calculated for incubation intervals of common interest $(24,30$, or $48 \mathrm{~h}$ ) was determined from $2 \mathrm{P}, 3 \mathrm{P}$, or M3P models of in vitro NDF disappearance (Table $5)$. The NDFD for all 3 incubation intervals varied with harvest date $(P<0.001)$ but not with disappearance model $(P \geq 0.151)$ or the harvest date $\times$ model interaction $(P \geq 0.986)$. As such, the mean of the 3 disappearance models for each field replicate was used as the dependent variable in regressions of NDFD on growth stage (Figure 7). The overall mean 24-h NDFD decreased from $66.9 \%$ at the stem elongation stage of growth to $23.0 \%$ at soft dough. With longer (30- or 48-h) incubation times, NDFD increased within harvest date relative to the $24-\mathrm{h}$ NDFD, but the range across all growth stages was similar for each incubation time
(43.9 to 45.7 percentage units of asNDFom). Regressions of NDFD on growth stage indicated that the $24-$ and $30-\mathrm{h}$ NDFD declined in quadratic $(P<0.001)$ relationships with growth stage characterized by very high coefficients of determination $\left(\mathrm{R}^{2} \geq 0.982\right)$. For the 48-h incubation, NDFD declined linearly $(P<0.001)$ with growth stage, but this simpler regression model was equally effective $\left(\mathrm{R}^{2}=0.985\right)$ at explaining declining NDFD as plants matured.

2017 Harvest. In vitro disappearance of asNDFom (NDFD) determined from single-endpoint incubations lasting 24, 36, or $48 \mathrm{~h}$ is summarized in Table 6. For plots harvested at the stem elongation stage of growth (May 24) and incubated in vitro for $24 \mathrm{~h}$, the mean NDFD (63.9\%) was similar to that for forages harvested at a similar growth stage the previous year and then declined to a minimum of $22.5 \%$ at the soft dough stage of growth. Within harvest date, NDFD increased with length of incubation. Averaged across all harvest dates, the mean differential between the 24- and 30-h incubations was 9.2 percentage units of asNDFom, and this mean differential increased to 13.2 percentage units for comparisons of 30- and 48-h incubations. Generally, regression relationships between NDFD and

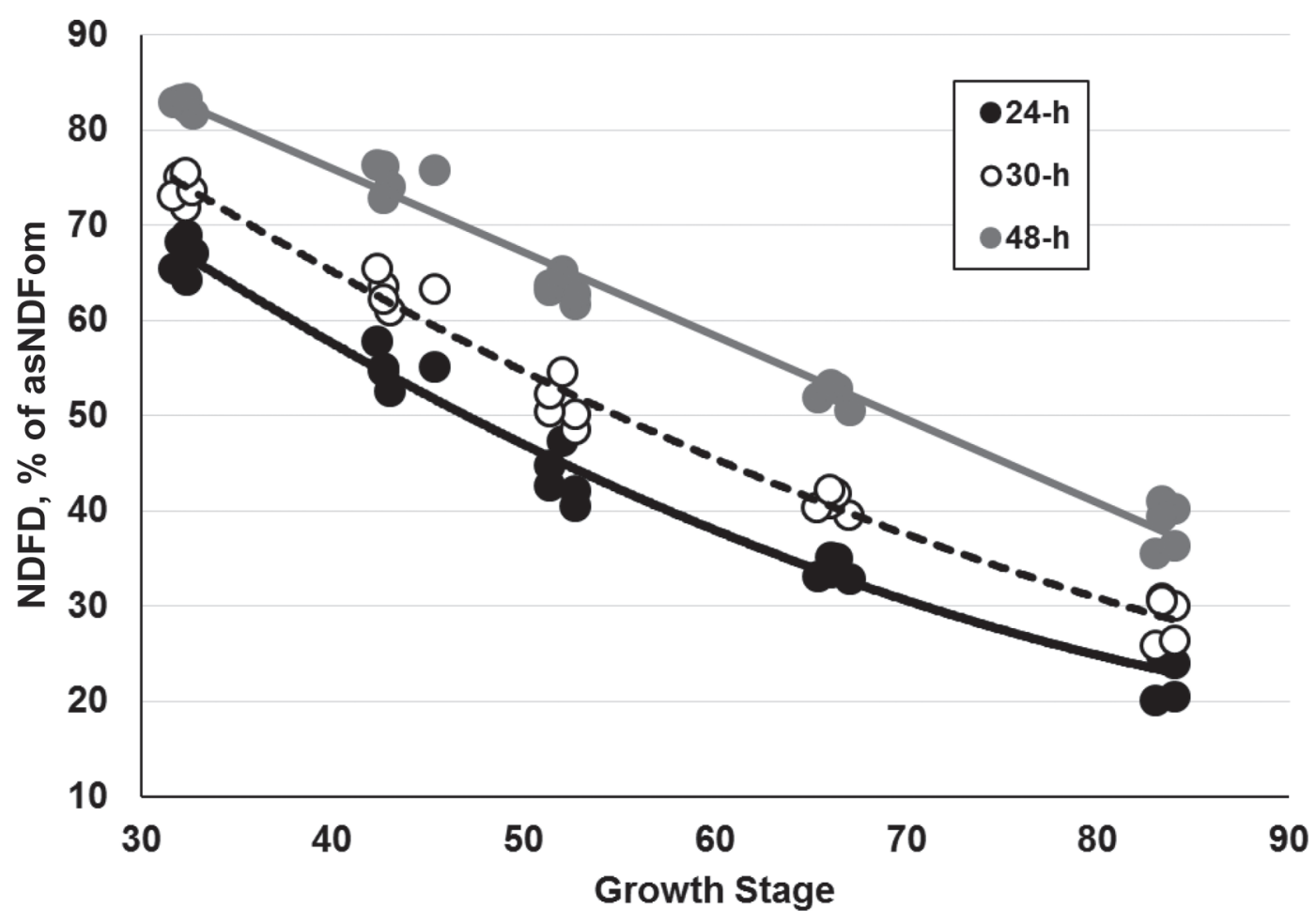

Figure 7. Determinations of in vitro disappearance of asNDFom (NDFD) after 24, 30, and $48 \mathrm{~h}$ for triticale forages harvested during 2016 at Marshfield, Wisconsin. Each estimate represents the mean NDFD as determined by 3 nonlinear regression models. Single-endpoint estimates of NDFD were regressed on growth stage at harvest and were fitted as follows: 24 -h NDFD ( $\%$ of asNDFom) $=0.00812 \mathrm{x}^{2}-1.79 \mathrm{x}+116.4, \mathrm{R}^{2}$ $=0.982$, root mean squared error $(\mathrm{RMSE})=2.21 \% ; 30$ - $\mathrm{NDFD}(\%$ of asNDFom $)=0.00649 \mathrm{x}^{2}-1.65 \mathrm{x}+120.6, \mathrm{R}^{2}=0.985, \mathrm{RMSE}=2.13 \%$; and 48 -h NDFD ( $\%$ of asNDFom $)=-0.877 \mathrm{x}+111.0, \mathrm{R}^{2}=0.985, \mathrm{RMSE}=2.06 \%$. 
growth stage at harvest (Figure 8) exhibited parallel responses among incubation times. Although the regression response for 24-h incubations on growth stage was best fitted to a quadratic $(P<0.001)$ model, the relationship had a high degree of linear character, and responses for 30- and 48-h incubations were best fitted to linear models, all of which exhibited high coefficients of determination $\left(R^{2} \geq 0.906\right)$. Overall, these regression responses were quite consistent with those observed for the previous year (Figure 7). Given that cultivars were not the same and that there were substantial differences in precipitation across years, these results suggest that growth stage at harvest is an effective predictor of fiber digestibility for winter triticale forages. In addition, regressions of NDFD, regardless of incubation time, on growth stage for these triticale forages were best fitted to lower-ordered polynomial models (linear or quadratic) compared with similar regressions of in vitro DM disappearance that were best fitted to cubic models (Coblentz et al., 2018). Conceptually, these differences are largely related to accumulation of WSC and starch in association with grain fill that is not relevant at advanced growth stages when only disappearance of asNDFom is considered. Unlike 2016, fraction $\mathrm{U}$ increased in a cubic $(P<0.001)$ relationship with growth stage (Figure 8); the higher-ordered nature of this response was due in part to a static response across the 2 early harvest dates, which was followed by steady increases thereafter.

\section{Regressions of NDFD on GDD $>5^{\circ} \mathrm{C}$}

Regressions of 24-, 30-, and 48-h incubations on GDD (Table 7) yielded either linear or quadratic $(P$ $<0.001$ ) relationships characterized by very high coefficients of determination $\left(\mathrm{R}^{2} \geq 0.926\right)$, which were consistent responses across production years. For both years, data from 24- and 30-h incubations were best fitted to quadratic models, but quadratic and linear responses were detected for the 48-h incubations during 2016 and 2017, respectively. A simple linear $(P<$ 0.001) regression response described the relationship between fraction $\mathrm{U}$ and GDD, thereby indicating that $\mathrm{U}$ increased by 6 percentage units of asNDFom for each 100 GDD accumulated during growth.

\section{CONCLUSIONS}

Current recommendations for harvesting triticale at boot stage in part prioritize an acceptable planting date for the subsequent crop of corn or soybeans and are not necessarily based on common trade-off considerations between DM yield and nutritive value. In central Wisconsin, triticale required 300 and 321 GDD during the

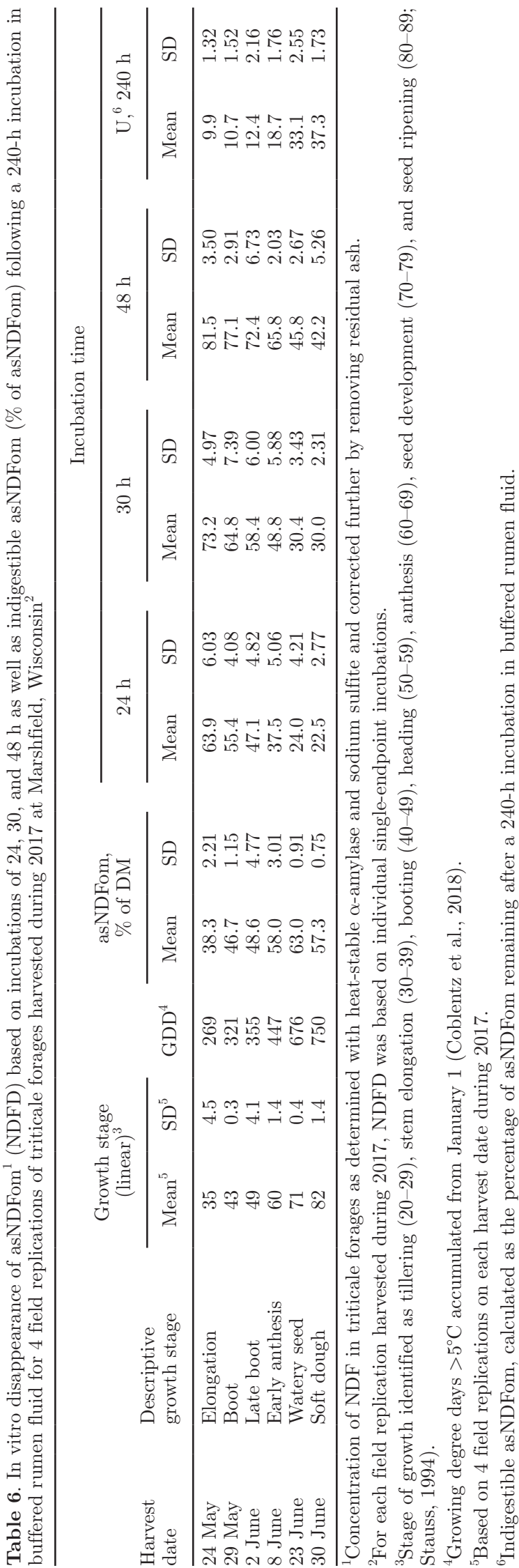

Journal of Dairy Science Vol. 101 No. 10, 2018 


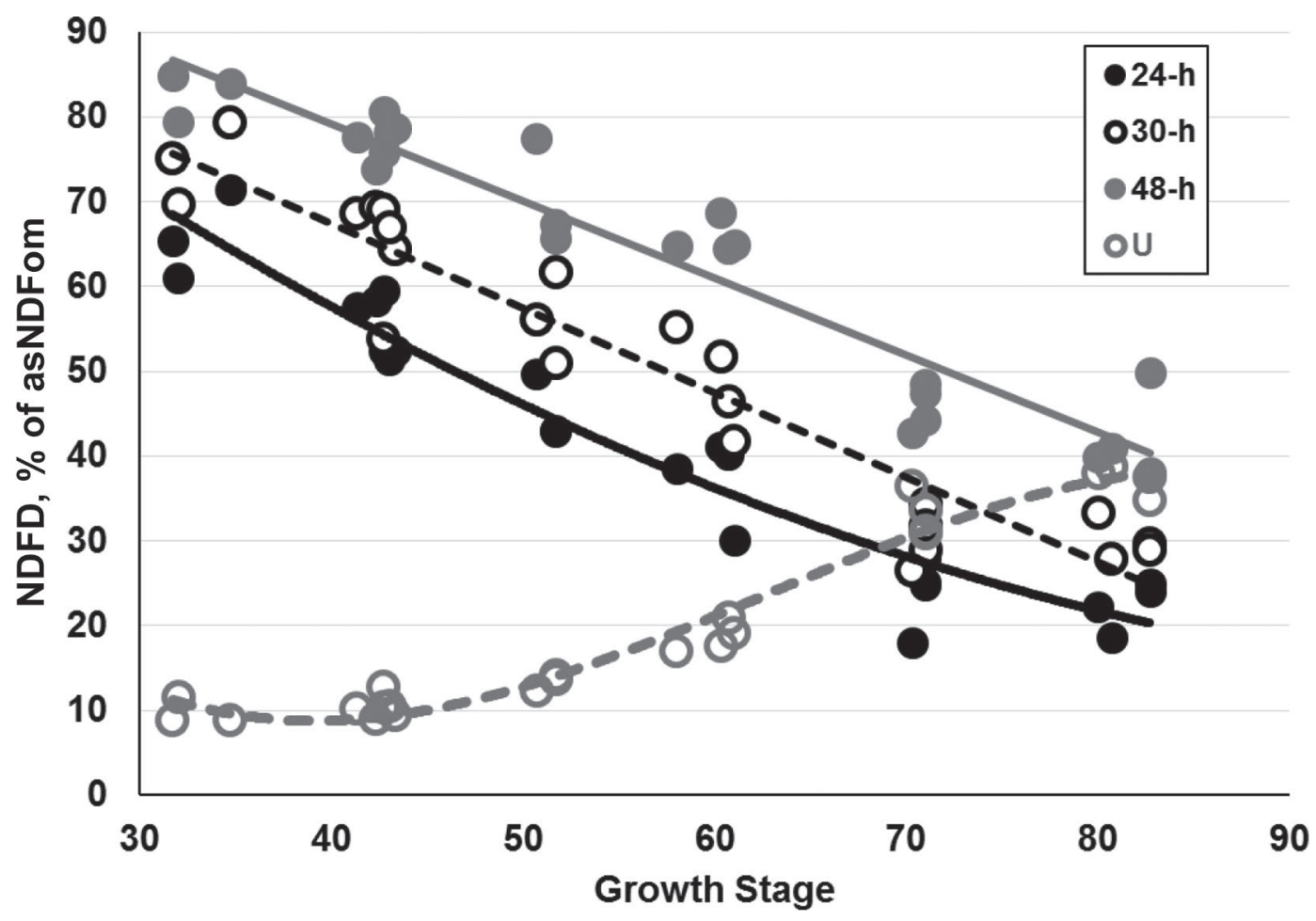

Figure 8. In vitro disappearance of asNDFom (NDFD) after 24-, 30-, and 48-h incubations as well as indigestible asNDFom based on the percentage of asNDFom remaining after a 240-h incubation in buffered rumen fluid (U) for triticale forages harvested during 2017 from 24 field plots at Marshfield, Wisconsin. Single-endpoint estimates of NDFD were regressed on growth stage at harvest and were fitted as follows: 24-h $\operatorname{NDFD}(\%$ of asNDFom $)=0.00858 \mathrm{x}^{2}-1.93 \mathrm{x}+121.0, \mathrm{R}^{2}=0.931$, root mean squared error (RMSE) $=4.44 \% ; 30-\mathrm{h}$ NDFD $(\%$ of asNDFom) $=-0.997 \mathrm{x}+107.3, \mathrm{R}^{2}=0.906, \mathrm{RMSE}=5.44 \% ; 48 \mathrm{~h} \mathrm{NDFD}(\%$ of asNDFom $)=-0.909 \mathrm{x}+115.5, \mathrm{R}^{2}=0.909, \mathrm{RMSE}=4.87 \%$; and $\mathrm{U}(\%$ of asNDFom $)=-0.000571 \mathrm{x}^{3}+0.107 \mathrm{x}^{2}-5.78 \mathrm{x}+104.9, \mathrm{R}^{2}=0.963, \mathrm{RMSE}=2.32 \%$

2016 and 2017 production years, respectively, to reach the boot stage of growth ( stage $=43$ ). This occurred during the last week of May, thereby permitting a subsequent double-cropping program despite the short growing season. Furthermore, a boot-stage harvest is compatible with the needs for highly digestible fiber in the diets of lactating dairy cows; the 30-h determinations of NDFD at boot stage for 2016 and 2017 were

Table 7. Regressions of in vitro disappearance of asNDFom ${ }^{1}$ on growing degree days $>5^{\circ} \mathrm{C}^{2}$ for triticale forages harvested during 2016 and 2017 at Marshfield, Wisconsin ${ }^{3}$

\begin{tabular}{|c|c|c|c|c|c|c|c|}
\hline Item & No. & Model type & Model & $P>F^{4}$ & $\begin{array}{l}\text { Dependent } \\
\text { mean }\end{array}$ & $\mathrm{RMSE}^{5}$ & $\mathrm{R}^{2}$ \\
\hline \multicolumn{8}{|l|}{2016} \\
\hline $24 \mathrm{~h}$ & 25 & Quadratic & $Y=0.000150 x^{2}-0.229 x+110.2$ & $<0.001$ & 44.5 & 1.99 & 0.986 \\
\hline $48 \mathrm{~h}$ & 25 & Quadratic & $\mathrm{Y}=0.000112 \mathrm{x}^{2}-0.193 \mathrm{x}+121.0$ & $<0.001$ & 62.5 & 1.89 & 0.988 \\
\hline \multicolumn{8}{|c|}{ F } \\
\hline $24 \mathrm{~h}$ & 24 & Quadratic & $Y=0.000211 x^{2}-0.299 x+128.6$ & $<0.001$ & 41.7 & 4.41 & 0.932 \\
\hline $\mathrm{U},{ }^{5} 240 \mathrm{~h}$ & 24 & Linear & $\mathrm{Y}=0.0601 \mathrm{x}-7.9$ & $<0.001$ & 20.3 & 1.93 & 0.972 \\
\hline
\end{tabular}

${ }^{1}$ Concentration of NDF in triticale forages as determined with heat-stable $\alpha$-amylase and sodium sulfite and corrected further by removing residual ash.

${ }^{2}$ Growing degree days $>5^{\circ} \mathrm{C}$ are summarized in Table 1 .

${ }^{3}$ Regressions include disappearance at 24,30 , and $48 \mathrm{~h}$ as well as indigestible asNDFom (U) calculated as the percentage of asNDFom remaining after a 240-h incubation in buffered rumen fluid. Unit for each dependent regression variable is percentage of asNDFom.

${ }^{4} P>F$ for the overall regression model.

${ }^{5}$ Root mean squared error for regression model. 
63.1 and $64.8 \%$ of asNDFom, respectively. Although harvesting at the soft dough stage has often been recommended for cereal grain forages and will likely maximize DM yield, this growth stage will not occur in central Wisconsin for triticale until about July 1, thereby precluding a subsequent crop of corn. Although the regression relationships between single-endpoint determinations of NDFD and growth stage were not consistently linear, all quadratic responses exhibited considerable linear character. Based on a 30-h incubation, NDFD declined by approximately 1 percentage unit for each growth stage unit, or about 10 percentage units as plant maturity progressed through each principal growth stage (e.g., booting, heading). While DM digestibility and energy density may improve with the physiological process of grain fill, NDFD is independent of this process and becomes very poor at advanced growth stages.

\section{ACKNOWLEDGMENTS}

Research was supported through appropriated USDA Agricultural Research Service (Washington, DC) CRIS funds (project no. 5090-12630-005-00D). Mention of trade names or commercial products in this article is solely for the purpose of providing specific information and does not imply either recommendation or endorsement by the USDA.

\section{REFERENCES}

Acosta, Y. M., C. C. Stallings, C. E. Polan, and C. N. Miller. 1991. Evaluation of barley silage harvested at boot and soft dough stages. J. Dairy Sci. 74:167-176.

Baron, V. S., A. Aasen, M. Oba, A. C. Dick, D. F. Salmon, J. A. Basarab, and C. F. Stevenson. 2012. Swath-grazing potential for small-grain species with a delayed planting date. Agron. J. 104:393-404.

Chandler, J. A., W. J. Jewell, J. M. Gossett, P. J. Van Soest, and J. B. Robertson. 1980. Predicting methane fermentation biodegradability. Biotechnol. Bioeng. Symp. 10:93-107.

Coblentz, W. K., M. S. Akins, K. F. Kalscheur, G. E. Brink, and J. S. Cavadini. 2018. Effects of growth stage and growing degree day accumulations on the quality characteristics of triticale forages: 1. Dry matter yield, nutritive value, and in vitro dry matter disappearance. J. Dairy Sci. 101:8965-8985.

Coblentz, W. K., and R. P. Walgenbach. 2010. In situ disappearance of dry matter and fiber from fall-grown cereal-grain forages from the north-central US. J. Anim. Sci. 88:3992-4005.

Edmisten, K. L., J. T. Green Jr., J. P. Mueller, and J. C. Burns. 1998. Winter annual small grain forage potential. I. Dry matter yield in relation to morphological characteristics of four small grain species at six growth stages. Commun. Soil Sci. Plant Anal. 29:867-879.

Flores, R., W. K. Coblentz, R. K. Ogden, K. P. Coffey, M. L. Looper, C. P. West, and C. F. Rosenkrans Jr.. 2007. Effects of fescue type and sampling date on the ruminal disappearance kinetics of autumn-stockpiled tall fescue. J. Dairy Sci. 90:2883-2896.
Gibson, L. R., C. D. Nance, and D. L. Karlen. 2007. Winter triticale response to nitrogen fertilization when grown after corn or soybean. Agron. J. 99:49-58.

Grant, R. 2015. Making milk with forage: Understanding rumen fiber dynamics. Pages 63-69 in Proc. Four-State Dairy Nutrition and Management Conference, Dubuque, IA.

Harper, M. T., J. Oh, F. Giallongo, G. W. Roth, and A. N. Hristov. 2017. Inclusion of wheat and triticale silage in the diet of lactating dairy cows. J. Dairy Sci. 100:6151-6163.

Hoffman, P. C., S. J. Sievert, R. D. Shaver, D. A. Welch, and D. K. Combs. 1993. In situ dry matter, protein, and fiber degradation of perennial forages. J. Dairy Sci. 76:2632-2643.

Kennelly, J. J., and Z. G. Weinberg. 2003. Small grains silage. Pages 749-780 in Silage Science and Technology. D. R. Buxton, R. E. Muck, and J. H. Harrison, ed. American Society of Agronomy, Crop Science Society of America, and Soil Science Society of America, Madison, WI.

Kilcer, T., J. Cherney, K. Czymmek, and Q. Ketterings. 2010. Winter triticale forage. Fact sheet no. 56. Cornell University Cooperative Extension, Ithaca, NY.

Maloney, T. S., E. S. Oplinger, and K. A. Albrecht. 1999. Small grains for fall and spring forage. J. Prod. Agric. 12:488-494.

McCartney, D. H., and A. S. Vaage. 1994. Comparative yield and feeding value of barley, oat, and triticale silages. Can. J. Anim. Sci. 74:91-96.

McCormick, J. S., R. M. Sulc, D. J. Barker, and J. E. Beuerlein. 2006. Yield and nutritive value of autumn-seeded winter-hardy and winter-sensitive annual forages. Crop Sci. 46:1981-1989.

McDonald, P., A. R. Henderson, and S. J. E. Heron. 1991. The Biochemistry of Silage. 2nd ed. Chalcombe, Buckinghamshire, UK.

Mertens, D. R. 2016. Using uNDF to predict dairy cow performance and design rations. Pages 12-19 in Proc. Four-State Dairy Nutrition and Management Conference, Dubuque, IA.

Mertens, D. R., and J. R. Loften. 1980. The effect of starch on forage fiber digestion kinetics in vitro. J. Dairy Sci. 63:1437-1446.

Nocek, J. E., and J. E. English. 1986. In situ degradation kinetics: Evaluation of rate determination procedures. J. Dairy Sci. 69:7787.

NRC. 2001. Nutrient Requirements of Dairy Cattle. 7th rev. ed. National Academy Press, Washington, DC.

Ørskov, E. R., and I. McDonald. 1979. The estimation of protein degradability in the rumen from incubation measurements weighted according to rate of passage. J. Agric. Sci. Camb. 92:499-503.

Raffrenato, E., and M. E. Van Amburgh. 2010. Development of a mathematical model to predict sizes and rates of digestion of a fast and slow degrading pool and the indigestible NDF fraction. Pages 52-65 in Proc. Cornell Nutrition Conference for Feed Manufacturers, East Syracuse, NY. Cornell University, Ithaca, NY.

Scarbrough, D. A., W. K. Coblentz, J. B. Humphry, K. P. Coffey, T. C. Daniel, T. J. Sauer, J. A. Jennings, J. E. Turner, and D. W. Kellogg. 2005. Evaluation of dry matter loss, nutritive value, and in situ dry matter disappearance for wilting orchardgrass and bermudagrass forages damaged by simulated rainfall. Agron. J. 97:604-614.

Schwarte, A. J., L. R. Gibson, D. L. Karlen, M. Liebman, and J. L. Jannink. 2005. Planting date effects on winter triticale dry matter and nitrogen accumulation. Agron. J. 97:1333-1341.

Stauss, R. 1994. Compendium of growth stage identification keys for mono- and dicotyledonous plants. Extended BBCH scale. CibaGeigy AG, Basel, Switzerland.

Van Soest, P. J. 1982. Nutritional Ecology of the Ruminant. Cornell Univ. Press, Ithaca, NY.

West, C. P., D. W. Walker, R. K. Bacon, D. E. Longer, and K. E. Turner. 1991. Phenological analysis of forage yield and quality in winter wheat. Agron. J. 83:217-224. 